\title{
A Perspective on the Contributions to Heterocyclic Chemistry by Professor Edward C. Taylor of Princeton University
}

\author{
Peter A. Jacobi \\ Department of Chemistry, Wesleyan University \\ Middletown, Connecticut 06457 \\ and \\ Stephen F. Martin \\ Department of Chemistry and Biochemistry \\ University of Texas, Austin, Texas 78712
}

For many years Professor Taylor has been one of the foremost heterocyclic chemists in the world, and there can hardly be a synthetic or medicinal chemist practicing today who has not utilized his contributions to heterocyclic synthetic methodology. In a broad sense, his vivid dramatization of the importance and effectiveness of how imagination can be exploited in heterocyclic synthesis stands as one his most important contributions. In his work, he has repeatedly demonstrated that rational syntheses of complex systems can be devised by sequential condensation, ring cleavage and rearrangement reactions. His development of novel and broadly useful synthetic methods in heterocyclic chemistry have made possible the preparation of many important natural products and biologically active compounds. His contributions are detailed in well over 400 papers, 35 patents and 74 edited or authored books.

Effective exploitation of rearrangements in synthesis has been one of his principal themes. Utilizing $o$ aminonitriles as intermediates, he developed simple routes to a broad variety of heterocyclic systems, and these extensive contributions to heterocyclic synthesis via $o$-aminonitriles were summarized in his book with Alexander McKillop, The Chemistry of Cyclic Enaminonitriles and o-Aminonitriles (1970). Extensions of his discovery of the base-catalyzed dimerization of $o$-aminonitriles $(48,72,82)$ led to a general synthetic method for 4-aminopyrimidines and a variety of other functionalized pyrimidines $(71,75,76,108,126$, $127,131,132,133,134,154)$. His preparation of malononitrile dimer. (57) and its utilization as an intermediate for the synthesis of condensed heterocycles (58) has been the basis for much further work by other research groups. An early example of his application of rearrangement reactions to heterocyclic synthesis was his preparation of the aglycone of the antibiotic toyocamycin from tetracyanoethylene (104, 112). He elucidated the structure of and then synthesized the pyrimidotriazine antibiotic 2-methylfervenulone (MSD-92) (164), and then devised an elegant one-step synthesis of the related antibiotic fervenulin (148, 239). Extensive work on purine chemistry $(28,39,41,42,49,53,54,55,64,70,71,81,87,106,107$, $111,160,199,215,328,372,383,387,390$ ) included an unequivocal synthesis of 9-substituted adenines 
via furazanopyrimidines (199) which has become a method of choice for the preparation of these critical nucleoside bases.

Taylor was one of the first to recognize and exploit the synthetic potential of the $N$-oxide grouping in aromatic nitrogen heterocyclic chemistry $(35,40,43,46,51,53,54,65,66,69,78,80,84,94,107,141$, $150,165,168,203,220,249$ ). His early synthesis of the alkaloid ricinine from 3-picoline (35), and his synthesis of xanthopterin from pterin-8-oxide (220), are outstanding examples of applications of $\mathrm{N}$-oxide rearrangements to synthesis. He developed a general and unequivocal route to aromatic $N$-oxides based upon intramolecular capture of hydroxylamines by suitably positioned electrophiles, and applied this method to the synthesis of, inter alia, quinoline, purine, quinazoline and quinoxaline $N$-oxides (165). His unequivocal synthesis of pteridines (see below) is based upon pyrazine $N$-oxide intermediates. His extensive work on the photochemistry of heterocyclic $N$-oxides $(88,89,98,117,129,157,163,170,172$, $183,187,190,191,203)$ includes a review of the field $(168)$.

Over the past forty years, Professor Taylor has contributed to the chemistry and synthesis of most of the common, and not-so-common, four-, five-, six- and seven-membered heterocyclic systems containing nitrogen, sulfur and/or oxygen, and he has introduced a host of new reagents for use in heterocyclic synthesis. He developed general procedures for the introduction of alkyl, alkenyl and epoxy groups into heterocyclic nuclei which were exploited in elegant total syntheses of the Cinchona alkaloids quinine, quinidine, cinchonine, and cinchonidine $(210,214,224,234)$; his strategies for the conversion of substituent primary amino groups into nitroso and nitro groups allow the ready conversion of heterocylic amino groups into a broad variety of other types of substituents $(304,305)$. Certainly his early one-step synthesis of tetrahydrocannabinol (THC) was one of his more dramatic illustrations of the power of imaginative synthetic planning (121). His recent applications of intramolecular Diels-Alder reactions of monocyclic and fused 1,2,4-triazines have led to a startling array of fused pyridine and pyrimidine systems $(325,330,331,339,340,341,348,349,351,352,357,358,360,362,363,365,366,370,374,375$, $376,380,391)$. Taylor's seminal papers on fused diazetidinones $(\beta$-azalactams) as highly strained bridgehead aza analogs of the $\beta$-lactam antibiotics $(155,156,294,298,299,301,312,313,315,317,337$, $338,353,399,401$ ) have stimulated intense interest.

Among Taylor's most significant contributions to heterocyclic chemistry have been his series of 78 papers on pteridines, and 49 papers on aza- and deaza-pteridines, extending over a period of more than 45 years. His early work dealt extensively with the development of synthetic methods to and the fundamental chemistry of these ring systems, and provided the background for much of the intensive present-day efforts in this important area of natural product and medicinal chemistry. He was one of the first to prepare 2,4diaminopteridines (4) and to demonstrate their activity as folic acid antimetabolites, and he elucidated the nature of a number of ring opening and rearrangement reactions which have since become standard for the introduction and manipulation of substituents in this system $(10-13,25-27,47,56,76)$. He was the first to 
demonstrate the synthetic versatility of pyrazines for pteridine synthesis $(16,29,34,38,41,47,60)$. This work culminated in a new synthetic approach to pteridines which makes possible the unequivocal preparation of 6-substituted derivatives uncontaminated by isomeric impurities; this "Taylor synthesis" is now considered a classic $(150,177,218,219)$. By utilization of this methodology, Taylor has described elegant syntheses of, inter alia, xanthopterin $(220,237,282)$, isoxanthopterin (237), folic acid (293), methotrexate, aminopterin, Cyprino-Pourpre B (221), L-erythro-biopterin (233, 250), neopterin, Asperopterin B (236), euglenapterin (300), 6-formylpterin $(267,285,356)$, deoxyurothione (303), urothione (373) and Form A of the molybdenum cofactor (including determination of its absolute configuration; 381, 385, 402).

Perhaps his most significant recent work in heterocyclic chemistry has come from extensions of these fundamental studies on synthesis and reactivity to the preparation of aza- and deaza-analogs of the various folate cofactors involved in metabolic one-carbon transfer reactions. A culmination of these efforts has been his design, synthesis and biological investigation of 5,10-dideaza-5,6,7,8-tetrahydrofolic acid (Lometrexol, DDATHF) $(327,328,343,344,345,350,371,372,379,382,383,384,386,387,388,389,390,393)$. This remarkable compound serves as a superb substrate for folylpolyglutamate synthetase (FPGS), and the resulting polyglutamate inhibits the enzyme glycinamide ribonucleotide formyltransferase (GARFT), which requires 10 -formyl-5,6,7,8-tetrahydrofolic acid as its natural cofactor, and mediates the first of two formyl transfer reactions in the de novo purine biosynthetic pathway. Inhibition of this process leads to depletion of cellular pools of both ATP and GTP. Lometrexol, which exhibits extraordinary activity against a broad range of solid tumors, and possesses complete activity against tumors resistant to Methotrexate, is now in worldwide Phase II clinical trials. Many further analogues of Lometrexol, which have been prepared by a diversity of ingenious synthetic strategies, include 5-deaza-5,6,7,8-tetrahydrofolic acid (378), 5,10-dideaza5,6,7,8-tetrahydrohomofolic acid $(384,408)$, 5,10-dideaza-10-hydroxymethyl-5,6,7,8-tetrahydrofolic acid (343), and "open-chain" analogues of Lometrexol in which the C-6 chiral center is eliminated by deletion of one of the flanking methylene groups $(404,406,409)$. In a very recent and extremely promising development, Taylor designed and synthesized a pyrrolo[2,3- $d$ ]pyrimidine derivative which is an extremely effective inhibitor of thymidylate synthase; this new antifolate entered clinical trial in the fall of 1992 for the treatment of solid tumors (410).

Taylor has also made invaluable contributions to the general literature and teaching of heterocyclic chemistry. In 1968 he joined Dr. Arnold Weissberger as co-editor of the Wiley-Interscience series,The Chemistry of Heterocyclic Compounds, and General Heterocyclic Chemistry (Taylor has been the sole editor since Dr. Weissberger's death a number of years ago). Thus far 61 volumes have been published under his editorship. His 24-hour Film Course on Principles of Heterocyclic Chemistry, and his companion Audio Course, both distributed by the American Chemical Society, are educational milestones; these have been followed recently by an extensive lecture course aimed at industrial research laboratories on Utilization of 
Heterocycles in Organic Synthesis. He is also the editor of Advances in Organic Chemistry (9 volumes to date) and was co-editor with Pfleiderer of Pteridine Chemistry (1964).

No listing of Professor Taylor's contributions to synthetic organic chemistry would be complete without mention of his contributions to the use of thallium reagents in organic synthesis. This extraordinarily productive research program, which he carried out over a period of some 17 years together with Dr. Alexander McKillop (a former postdoctoral associate, who is now Professor of Organic Chemistry at the University of East Anglia), led to more than 130 new chemical transformations which are applicable to aliphatic, alicyclic, aromatic and heterocyclic chemistry, and have astonishing versatility, scope, specificity and manipulative simplicity. For example, Taylor and his collaborators developed new methods for the synthesis of aromatic nitriles, phenols, thiophenols, thiocyanates, amines, iodides, bromides, chlorides, fluorides, nitroso and nitro compounds; for specific labelling of aromatic hydrocarbons with deuterium and tritium; for the synthesis of symmetrical and unsymmetrical biphenyls; and for orientation control in electrophilic aromatic substitution reactions. They developed new methods for the synthesis of carbonyl compounds, for ring contractions, ring expansions, and cyclizations, for functionalization of acetylenes, imines, and other unsaturated systems, for the synthesis of allenes and acetylenes from $\beta$-keto esters, for glycol synthesis and cleavage, for the synthesis of arylacetic esters from aralkyl ketones by oxidative rearrangement, for the conversion of cinnamaldehydes to arylmalondialdehydes, and for the synthesis of both benzoxazoles and indoles from anilides. Novel, effective procedures were developed for the replacement of phenolic - $\mathrm{OH}$ groups by a variety of other functional groups, including carbon substituents. Taylor was able to immobolize thallium reagents on inert inorganic supports, and many of the above reactions can now be carried out simply by passing a solution of the substrate through a column packed with the supported thallium reagent. This monumental work on thallium chemistry is described in a series of almost seventy papers on "Thallium in Organic Synthesis" (see bibliography for citations) and five extensive reviews, and was recognized, together with his work in heterocyclic chemistry, in the 1974 ACS Award for Creative Work in Synthetic Organic Chemistry. 


\section{EDWARD C. TAYLOR}

\section{Articles}

1. Pyrimido(4,5-b)pyrazines. I. Synthesis of 6,7-Symmetrically Substituted Derivatives (with C.K. Cain and M.F. Mallette), J. Am. Chem. Soc., 68, 1996 (1946).

2. Pyrimido(4,5-b)pyrazines. II. 2,4-Diaminopyrimido(4,5-b)pyrazine and Derivatives (with M.R. Mallette and C.K. Cain), J. Am. Chem. Soc., 69, 1814 (1947).

3. Pyrimido(4,5-b)pyrazines (Pteridines). III. Pteridinemono- and Dicarboxylic Acids (with C.K. Cain and M.F. Mallette), J. Am. Chem. Soc., 70, 3026 (1948).

4. Pteridines. IV. Derivatives of 2,4-Diamino-6,7-diphenylpteridine (with C.K. Cain and L.J. Daniel), J. Am. Chem. Soc., 71, 892 (1949).

5. The Hydrolysis of Amino Groups in Certain 2,4,5,6-Tetra-substituted Pyrimidines (with C.K. Cain), J. Am. Chem. Soc., 71, 2282 (1949).

6. Pteridines. V. Deamination Studies on Certain Aminopteridines (with C.K. Cain), J. Am. Chem. Soc., 71, 2538 (1949).

7. Zur Kenntnis der Triterpene. 157. Uber Zusammenhange zwischen Gypsogenin, Hederagenin und Quillajasaure (with L. Ruzicka, B. Bischof, A. Meyer and O. Jeger), Collection of Czechoslovak Chemical Communications, 15,893 (1950).

8. Pteridines. VI. Replacement Reactions of Amino, Hydroxyl and Mercapto Groups in the Pteridine Series (with C.K. Cain), J. Am. Chem. Soc., 73, 4384 (1951).

9. A New Synthesis of 4,6-Diamino-2,5-dichloropyrimidine (with P. Drenchko), J. Am. Chem. Soc., 74, 1101 (1952).

10. Pteridines. VII. The Synthesis of 2-Alkylaminopteridines (with C.K. Cain), J. Am. Chem. Soc., 74, 1644 (1952).

11. Pteridines VIII. The Synthesis of 2,4-bis-(Alkylamino)-6,7-diphenylpteridines, J. Am. Chem. Soc., 74, 1648 (1952).

12. Studies on the Aminolysis of Heterocyclic Amides. I. The Aminolysis of 6,7-Diphenyllumazine, J. Am. Chem. Soc., 74, 1651 (1952).

13. Pteridines. IX. Hydrolytic Ring Cleavage of 3-Benzyl-6,7-diphenyl-4(3H)-pteridinone, J. Am. Chem, Soc., 74, 2380 (1952).

14. A New Synthesis of Phenanthridine (with A.E. Martin), J. Am. Chem. Soc., 74, 6295 (1952).

15. The Structures of Some Alleged Dihydroindoles (with N.W. Kalenda), J. Org. Chem., 18, 1755 (1953).

16. Pteridines. X. A New Approach to the Synthesis of Pteridines (with J.A. Carbon and D.R. Hoff), J. Am.Chem. Soc., 75, 1904 (1953).

17. A New Route to Pteridine-6-Carboxylic Acids (with H.M. Loux), Chem. and Ind., 1585 (1954). 
18. Pyridine-1-Oxides. I. Synthesis of Some Nicotinic Acid Derivatives (with A.J. Crovetti), J. Org. Chem., 19, 1633 (1954).

19. The Synthesis of Some s-Triazolo(4,3-b)-as-triazines (with W.H. Gumprecht and R.F. Vance), J. Am. Chem. Soc., 76, 619 (1954).

20. Improved Phenanthridine Synthesis with Polyphosphoric Acid (with N.W. Kalenda), J. Am. Chem. Soc., 76, 1699 (1954).

21. The Reaction of $\alpha$-Cyanobenzyl Benzenesulfonate with Thioureas (with J. Wolinsky and H.-H. Lee), J. Am. Chem. Soc., 76, 1866 (1954).

22. The Reaction of $\alpha$-Cyanobenzyl Benzenesulfonate with Dithiocarbamates (with J. Wolinsky and H.-H. Lee), J. Am. Chem. Soc., 76, 1870 (1954).

23. The Preparation and Identity of Phenylmaleic Acid and Phenylfumaric Acid (with E.J. Strojny), J. Am. Chem. Soc., 76, 1972 (1954).

24. Pteridines. XI. The Structure of Wieland's 'Bis-Alloxazine' (with C.K. Cain and H.M. Loux), J. Am. Chem. Soc., 76, 1874 (1954).

25. Ring-Opening Reactions of Pteridines, in Chemistry and Biology of Pteridines, J. and A. Churchill, Ltd., London, pp. 2-34 (1954).

26. Recent Developments in Pteridine Chemistry (with J.A. Carbon, R.B. Garland, D.R. Hoff, C.F. Howell and W.R. Sherman), in Chemistry and Biology of Pteridines, J. and A. Churchill, Ltd., London, pp. 104-120 (1954).

27. Structural Studies on Pyrimidopteridines. The Structure of 'Bis-Alloxazine' and 'Diuracilpyridazine', Chemistry and Biology of Pteridines, J. and A. Churchill, Ltd., London, pp. 193-200 (1954).

28. Eine Neue Synthese von Purinen (with E. Richter), Angew. Chem., 67, 303 (1955).

29. A New Route to 4-Aminopteridines (with W.W. Paudler), Soc. Chem. Ind., 74, 1061 (1955).

30. The Reaction of 5,5-Dihalobarbituric Acids with Pyridine (with W.W. Paudler and C.K. Cain), J. Org. Chem., 20, 264 (1955).

31. Pyrimidopteridines by Oxidative Self-Condensation of Aminopyrimidines (with H.M Loux, E.A. Falco and G.H. Hitchings), J. Am. Chem. Soc., 77, 2243 (1955).

32. The Synthesis of 4-Amino-2,5-Diphenylthiazole (with J.A. Anderson and G.A. Berchtold),J. Am. Chem. Soc., 77, 5444 (1955).

33. The Synthesis of N-Methyl-3-Cyano-4-Methoxy-6-Pyridone. A Structural Isomer of Ricinine (with A.J. Crovetti and H.M. Loux), J. Am. Chem. Soc., 77, 5445 (1955).

34. Pteridines. XIV. Further Studies on a New Approach to Pteridine Synthesis (with R.B. Garland and C.F. Howell), J. Am. Chem. Soc., 78, 210 (1956).

35. Pyridine-1-Oxides. II. A New Synthesis of Ricinine (with A.J. Crovetti), J. Am. Chem. Soc., 78, 5104 (1956).

36. Phenanthridine Syntheses via the Diels-Alder Reaction. A New Route to 6(5H)-Phenanthridinone (with E.J. Strojny), J. Am. Chem. Soc., 78, 5104 (1956). 
37. The Synthesis of Pyrimido(4,5-b)quinolines (with N.W. Kalenda), J. Am. Chem. Soc., 78, 5108 (1956).

38. A New Synthetic Approach to Pteridines (with T.S. Osdene), J. Am. Chem. Soc., 78, 5451 (1956).

39. Studies in Purine Chemistry. New Routes to Certain 2,1,3-Triazoles, Pyrimidines and 2,1,3Triazolo(4,5-d)pyrimidines (with E. Richter), J. Am. Chem. Soc., 78, 58489 (1956).

40. 3-Methyl-4-nitropyridine-1-Oxide (with A.J. Crovetti), Organic Syntheses, 36, 53 (1956).

41. Some Synthetic Studies on Purines and Related Heterocycles (with T.S. Osdene, E. Richter and O. Vogl), in Chemistry and Biology of Purines, J. and A. Churchill, Ltd., London, pp. 20-33 (1957).

42. A Facile Synthesis of 2-Substituted Adenines (with O. Vogl), J. Am. Chem. Soc., 79, 1518 (1957).

43. Pyridine-1-Oxides. III. Oxidative Coupling of 4-Nitro-3-Picoline-1-Oxide (with A.J. Crovetti and N.E. Boyer), J. Am. Chem. Soc., 79, 3549 (1957).

44. 2-Chloronicotinonitrile (with A.J. Crovetti), Organic Syntheses, 37, 12 (1957).

45. Diaminouracil Hydrochloride (with W.R. Sherman), Organic Syntheses, 37, 15 (1957).

46. Nicotinamide-1-Oxide (with A.J. Crovetti), Organic Syntheses, 37, 63 (1957).

47. Pteridines. XVI, A Synthesis of 2-Aminopyrazine-3-Carboxamides by Reductive Ring Cleavage of 3Hydroxy-1-Pyrazolo(b)pyrazines (with J.W. Barton and T.S. Osdene), J. Am. Chem. Soc., 80, 421 (1958).

48. The Dimerization of 2-Aminonicotinonitrile (with A.J. Crovetti and R.J. Knopf), J. Am. Chem. Soc., 80, 427 (1958).

49. Studies in Purine Chemistry. VI. A Convenient One-Step Synthesis of Hypoxanthine (with C.C. Cheng), Tetrahedron Lett., 12, 9 (1959).

50. Selective Reduction of a Benzyloxyamino Group in the Presence of a Nitro Group (with J.W. Barton), J. Org. Chem., 24, 127 (1959).

51. Pyridine-1-Oxides. IV. Nicotine-1-oxide, Nicotine-1'-Oxide and Nicotine-1,1'-dioxide (with N.E. Boyer), J. Org. Chem., 24, 275 (1959).

52. Pteridines. XXI. A One-Step Synthesis of 4-Aminopteridines (with C.C. Cheng), J. Org. Chem., 244, 2019 (1959).

53. Studies in Purine Chemistry. IV. Hypoxanthine-1-N-Oxide (with C.C. Cheng and O. Vogl), J. Org. Chem., 24, 2019 (1959).

54. Studies in Purine Chemistry. V. 7-Methyladenine-3-N-Oxide (with P.K. Loeffler), J. Org. Chem., 24, 2035 (1959).

55. Studies in Purine Chemistry. II. A Facile Synthesis of 2-Substituted Adenines (with O. Vogl and C.C. Cheng), J. Am. Chem. Soc., 81, 2442 (1959).

56. Synthesis of 2-Aminonicotinamides by Raney Nickel Cleavage of Pyrazolo(3,4-b)pyridines (with J.W. Barton), J. Am. Chem. Soc., 81, 2448 (1959).

57. The Reaction of Malononitrile with Hydrazine (with K.S. Hartke), J. Am. Chem. Soc., 81, 2452 (1959). 
58. The Reaction of Malononitrile with Substituted Hydrazines: New Routes to 4-Aminopyrazolo(3,4d)pyrimidines (with K.S. Hartke), J. Am. Chem. Soc., 81, 2456 (1959).

59. Pteridines. XVII. Reactions of 2,4,6,7-Tetrachloropteridine. The Synthesis of 5,6,7,8Tetrahydropteridine (with W.R. Sherman), J. Am. Chem. Soc., 81, 2464 (1959).

60. Pteridines. XVIII. A Direct Synthesis of 2-Aminopyrazine-3-carboxamides (with O. Vogl), J. Am. Chem. Soc., 81, 2472 (1959).

61. Pteridines. XIX. A Synthesis of 8-Substituted Pteridine-6-Carboxylic Acids (with H.M. Loux), J. Am. Chem. Soc., 81, 2474 (1959).

62. Pteridines. XX. 3-Amino-4(3H)-Pteridinone (with O. Vogl and P.K. Loeffler), J. Am.Chem. Soc., 81, 2479 (1959).

63. Photodimerization of $\alpha, \beta$-Unsaturated Lactams (with W.W. Paudler), Tetrahedron Lett., 25,1 (1960).

64. Studies in Purine Chemistry. VII. An Improved Synthesis of Hypoxanthine (with A.J. Crovetti), J. Org. Chem., 25, 850 (1960).

65. Pyridine 1-Oxides. VI. Synthesis of Some 3-Styrylpyridine 1-Oxides (with A.J. Crovetti), J. Org. Chem., 25, 850 (1960).

66. Pryidine 1-Oxides. VII. 3-Nitropyridine 1-Oxide (with J.S. Driscoll), J. Org. Chem., 2ㄷ, 1716 (1960).

67. A New Synthesis of Aliphatic and Aromatic Thioamides from Nitriles (with J.A. Zoltewicz), J. Am. Chem. Soc., 82, 3138 (1960).

68. A Convenient Synthesis of Formamidine and Acetamidine Acetate (with W.A. Ehrhart), J. Am. Chem. Soc., $8 \underline{2}, 3138$ (1960).

69. Pyridine 1-Oxides. V. 4-Substituted Nicotinic Acid 1-Oxides (with J.S. Driscoll), J. Am. Chem. Soc., $82,3141(1960)$.

70. Studies in Purine Chemistry. VIII. A Convenient Synthesis of Hypoxanthines and Adenines (with E. Richter and J.E. Loeffler), J. Am. Chem. Soc., 82, 3144 (1960).

71. Studies in Purine Chemistry. IX. A New Pyrimidine Synthesis from o-Aminonitriles (with P.K. Loeffler), J. Am. Chem. Soc., 82, 3147 (1960).

72. The Dimerization of 2-Amino-5-nitrobenzonitrile (with R.J. Knopf and A.L. Borror), J. Am. Chem. Soc., 82,3152 (1960).

73. Pteridines. XXII. 5,8-Dihydropteridines by Sodium Borohydride Reduction (with W. Pfleiderer), J. Am. Chem. Soc., 82, 3765 (1960).

74. The Synthesis of Some Model Compounds Related to Tetrahydrocannabinol (with E.J. Strojny), J. Am. Chem. Soc., 82, 5198 (1960).

75. Pyrimido(4,5-b)pyrimidines. Part I. (with R.J. Knopf, R.F. Meyer, A. Holmes and M.L. Hoefle), J. Am. Chem. Soc., 82, 5711 (1960).

76. A Facile Pyrimidine Ring Cleavage (with R.J. Knopf, J.A. Cogliano, J.W. Barton and W. Pfleiderer), J. Am. Chem. Soc., 82, 6058 (1960).

77. Some Further Reactions of $\alpha$-Cyanobenzyl Benzenesulfonate (with G.A. Berchtold, N.A. Goeckner and F.G. Stroehmann), J. Org. Chem., 26, 2715 (1961). 
78. Pyridine 1-Oxides. VIII. Hydrolysis of 4-Nitro-3-picoline (with J.S. Driscoll), J. Org. Chem., 26, 3001 (1961).

79. A New Intermolecular Hydrogen-Transfer Reaction (with M.J. Thompson), J. Org. Chem.,26, 3769 (1961).

80. Pyridine 1-Oxides. IX. Further Oxidative Dimerizations of 4-Nitro-3-picolines (with J.S. Driscoll), J. Org. Chem., 26, 3769 (1961).

81. Studies in Purine Chemistry. X. Some Derivatives of 9-Aminopurines (with J.W. Barton and W.W. Paudler), J. Org. Chem., 26, 4961 (1961).

82. The Reaction of Nitriles with o-Aminonitriles: A Convenient Synthesis of Fused 4-Aminopyrimidines (with A.L. Borror), J. Org. Chem., 26, 4967 (1961).

83. On the Reaction of 2,4-Dichloro-5-nitropyrimidine with Amines (with M.J. Thompson), J. Org. Chem., 26, 5224 (1961).

84. Pyridine 1-Oxides. X. $\mathrm{pK}_{\mathrm{a}}$ Values for Some 4-Substituted Nicotinic Acid 1-Oxides (with J.S. Driscoll and W. Pfleiderer), J. Org. Chem., 26, 5230 (1961).

85. A Convenient Synthesis of Fused 4-Mercaptopyrimidines from o-Aminonitriles (with J.A. Zoltewicz), J. Am. Chem. Soc., 83, 248 (1961).

86. A Novel Rearrangement of Pyrimidines to s-Triazines (with C.W. Jefford and C.C. Cheng), J. Am. Chem. Soc., 83, 1261 (1961).

87. Purine Nucleosides. I. The Synthesis of Certain 6-Substituted 9-(Tetrahydro-2-pyranyl)purines as Models of Purine Deoxynucleosides (with R.K. Robins, E.F. Godefroi, L.R. Lewis and A. Jackson), J. Am. Chem. Soc., 83, 2574 (1961).

88. A Photochemically Induced, Valence-Bond Tautomerism in a Six-membered Aromatic System (with W.W. Paudler and I. Kuntz), J. Am. Chem. Soc., 83, 2967 (1961).

89. The Photolysis of 2-Aminopyridines and 2-Pyridones (with R.O. Kan and W.W. Paudler), J. Am. Chem. Soc., 83, 4484 (1961).

90. Structure of the Alleged Diels-Alder Adduct from 2,3-Dimethylquinoxaline and Maleic Anhydride (with E.S. Hand), Tetrahedron Lett., 25, 1225 (1962).

91. Reaction of Anthranilonitrile and N-Methylanthranilonitrile with Phenyl Isocyanate and Phenyl Isothiocyanate (with R.V. Ravindranathan), J. Org. Chem., 27, 2622 (1962).

92. Structure of the Alleged Diels-Alder Adduct from 2,3-Dimethylquinoxaline and Quinone (with E.S. Hand), J. Org. Chem., 27, 3734 (1962).

93. The Rearrangement of 5-Nitroso-6-aminopyrimidines to s-Triazines (with C.W. Jefford), J. Am. Chem. Soc., 84, 3744 (1962).

94. New Routes to Diazine-Mono-N-Oxides (with C.W. Jefford), Chem. and Ind., 1559 (1963).

95. A Synthesis of 5-Chloro-6-ethoxypyrimidines (with J.E. Loeffler and B. Mencke), J. Org. Chem., 28, 509 (1963).

96. A Convenient Synthesis of N,N-Disubstituted Formamidines and Acetamidines (with W.A. Ehrhart), J. Org. Chem., 28, 1108 (1963). 
97. Structures of Some Alleged Diels-Alder Adducts from 2,3-Dimethylquinoxaline (with E.S. Hand), J. Am. Chem. Soc., 85, 770 (1963).

98. Photochemical Dimerization of 2-Aminopyridines and 2-Pyridones (with R.O. Kan), J. Am. Chem. Soc., 85, 776 (1963).

99. Die Synthese von Pyrimido(4,5-ê)-as-Triazinen(6-Aza-Pteridinen) (with R.W. Morrison, Jr.), Angew. Chem., 76, 342 (1964).

100. The Mechanism of the Conversion of $\mathrm{Q}-\mathrm{Nitrobenzoyldiazomethane} \mathrm{to} \mathrm{N-Hydroxyisatin} \mathrm{(with} \mathrm{D.R.}$ Eckroth), Tetrahedron, 20, 2059 (1964).

101. The Synthesis of 4-Aminoisoxazolo(5,4-d)pyrimidines (with E.E. Garcia), J. Org. Chem., 29, 2116 (1964).

102. Synthesis of Some $(1,2,3)$ Thiadiazolo(5,4-d)pyrimidines and Pyrimido(4,5-b $)(1,4)$ thiazines (with E.E. Garcia), J. Org. Chem., 29, 2121 (1964).

103. Long Range Deshielding by Chlorine (with G.W.H. Cheeseman and R.C. Fort, Jr.), J. Org. Chem., 29 , 2440 (1964).

104. Synthesis of 4-Amino-5-cyanopyrrolo(2,3-d)pyrimidine, the Aglycone of Toyocamycin (with R.W. Hendess), J. Am. Chem. Soc., 86, 951 (1964).

105. Synthesis and Properties of Pyrrolo(1,2-a)quinoxaline (with G.W.H. Cheeseman), J. Am. Chem. Soc., 86, 1830 (1964).

106. Studies in Purine Chemistry. XI. A New Purine Synthesis (with E.E. Garcia), J. Am. Chem. Soc., 86 , 4720 (1964).

107. Studies in Purine Chemistry. XII. Synthesis of 8-Substituted Theophyllines. Isolation of a 7-N-Oxide Intermediate and an Unusual Leuckart Reduction with Dimethylformamide (with E.E. Garcia), J. Am. Chem. Soc., 86, 4721 (1964).

108. A Facile Synthesis of Fused 4-Mercaptopyrimidines (with S. Vromen), Israel J. Chem., 2, 3101 (1964).

109. Synthesis with Properties of 5,6- and 4,8-Dihydropteridine Isomers (with M.J. Thompson and W. Pfleiderer), in Pteridine Chemistry, Pergamon Press, Oxford, pp. 181-205 (1964).

110. New Synthesis of Pyrrolo(2,3-d) and Pyrrolo(3,2-d)pyrimidines (with E.E. Garcia), J. Org. Chem., 30, 655 (1965).

111. Studies in Purine Chemistry. Part XIII. Synthesis of the 5-Aza Analogs of Adenine and Hypoxanthine (with R.W. Hendess), J. Am. Chem. Soc., 87, 1980 (1965).

112. Synthesis of Pyrrolo(2,3-d)pyrimidines: The Aglycone of Toyocamycin (with R.W. Hendess), J. Am. Chem. Soc., 87, 1995 (1965).

113. Facile Reductive Cyclizations: New Routes to Heterocycles. Part I. (with A. McKillop), J. Am. Chem. Soc., 87, 1984 (1965).

114. Facile Reductive Cyclizations: New Routes to Heterocycles. Part II. (with A. McKillop and R.E. Ross), J. Am. Chem. Soc., 87, 1990 (1965).

115. A Synthesis of Pyrimido(5,4-ê)-as-Triazines (6-Azapteridines) (with R.W. Morrison, Jr.), J. Am. Chem. Soc., 87, 1976 (1965). 
116. A New Synthesis of 5-Nitropyrimidines (with A. McKillop), J. Org. Chem., 30, 3153 (1965).

117. Photochemical Interactions in ortho, ortho'-Disubstituted Biphenyls (with B. Furth and M. Pfau), J. Am. Chem. Soc., 87, 1400 (1965).

118. Reaction of 2,3-Diphenylquinoxaline with Amide Ion. An Unusual Ring Contraction (with A. McKillop), J. Org. Chem., 30, 2858 (1965).

119. Bildung eines 2-Thioxyanotopyrimidins aus einem 1-Amino-2-thioxo-1,2-dihydropyrimidin und Dimethylformamid/Phosphoroxychlorid (with R.W. Morrison, Jr.), Angew. Chem., 77, 859 (1965).

120. 3-Cyano-4-aminopyrazolo(3,4-d)pyrimidine, an Azalog of the Aglycone of Toyocamycin (with A. AbulHusn), J. Org. Chem., 31, 342 (1966).

121. Active Constituents of Hashish. Synthesis of d,1- $\Delta^{6}-3,4$-trans-Tetrahydrocannabinol (with $K$. Lenard and Y. Shvo), J. Am. Chem. Soc., 8, 367 (1966).

122. Synthesis and Properties of Some Indole Derivatives Related to Cypridina Luciferin (with H.-D. Stachel, O. Shimomura and F.H. Johnson), Bioluminescence in Progress, ed. by Johnson and Haneda, Princeton University Press, 1966, p. 51.

123. Chemiluminescence and Fluorescence of Cypridina Luciferin and of Some New Indole Compounds in Dimethylsulfoxide (with F.H. Johnson, H.-D. Stachel and O. Shimomura), Bioluminescence in Progress, ed. by Johnson and Haneda, Princeton University Press, 1966, p. 67.

124. Application of the Haloalkoxy Reaction to 6-Nitroanthroxanic Acid (with D.R. Eckroth and T.G. Chochran), J. Org. Chem., 31, 1303 (1966).

125. Formamidine Acetate (with W.A. Ehrhart and M. Kawanisi), Organic Syntheses, $\underline{46}, 39$ (1966).

126. Eine neue Synthese 5-substituierter Pyrimidine (with J.G. Berger), Angew. Chem., 78, 144 (1966).

127. Einstufige Synthese Anellierter Pyrimidindithione (with R.N. Warrener and A. McKillop), Angew. Chem., 78, 333 (1966).

128. Synthese Anellierter Pyrimidinthione aus $\mathrm{q}-$ Aminonitrilen (with S. Vromen, A. McKillop and R.V. Ravindranathan); Angew. Chem., 78, 332 (1966).

129. Group Migration in the Photolysis of 6-Substituted Phenanthridine 5-Oxides (with G.G. Spence), Chemical Communications, $\underline{21}, 767$ (1966).

130. A New Synthesis of Diethyl B-Ketoadipate (with A. McKillop), Tetrahedron, 23, 897 (1967).

131. A Simple, One-Step Synthesis of Fused Pyrimidinethiones (with A. McKillop and S. Vromen), Tetrahedron, $\underline{23}, 885$ (1967).

132. Heterocyclic Syntheses from o-Aminonitriles. Part XXVII. A One-Step Synthesis of Fused Pyrimidinedithiones (with A. McKillop and R.N. Warrener), Tetrahedron, 23, 891 (1967).

133. Heterocyclic Syntheses from o-Aminonitriles. Part XXVIII. Synthesis of Some Benzo(f)- and Benzo(h)quinazolines (with A. McKillop, Y. Shvo and G.H. Hawks), Tetrahedron, 23, 2081 (1967).

134. Heterocyclic Syntheses from o-Aminonitriles. Part XXIX. A New Synthesis of 5-Substituted Pyrimidines (with J.G. Berger), J. Org. Chem., 32, 2376 (1967).

135. A Convenient Synthesis of Dimethyl 4-Phenylacridinates (with N.D. Heindel), J. Org. Chem., $\underline{32}, 1666$ (1967). 
136. Tetrahydrocannabinol Analogs. Synthesis of 2-(3-Methyl-2-oxtyl)-3-hydroxy-6,6,9-trimethyl-7,8,9,10tetrahydrobenzo(b,d)pyran (with K. Lenard and B. Loev), Tetrahedron, 23, 77 (1967).

137. The Reaction of Anthranil with N-Phenylmaleimide. (with D.R. Eckroth and J. Bartulin), J. Org. Chem., 32, 1899 (1967).

138. A Ready Total Synthesis of 8,13-Diaza-18-noroestrone Methyl Ethers (with K. Lenard), Chem. Commun., 27 (1967).

139. A Convenient Oxidation of Hydroxylamines to Nitroso Compounds (with F. Yoneda), Chem. Commun., 199 (1967).

140. Chemical Shift Nonequivalence of Diastereotopic Protons Due to Restricted Rotation around ArylNitrogen Bonds in Substituted Amides (with Y. Shvo, K. Mislow and M. Raban), J. Am. Chem. Soc., 89, 4910 (1967).

141. Ring Expansion of Anthranil to Quinoline 1-Oxides (with J. Bartulin), Tetrahedron Lett., 25, 2337 (1967):

142. New Syntheses of Alloxazines (with F. Sowinski, T. Yee and F. Yoneda), J. Am. Chem. Soc., 89, 3369 (1967).

143. An Unusual Molecular Rearrangement of an N-Aminopyrimidine (with R.W. Morrison, Jr.), J. Org. Chem., 32, 2379 (1967).

144. Kondensierte Imidazole aus Q-Diaminen and Isatosaure-anhydriden (with F. Yoneda), Angew. Chem., 79, 901 (1967).

145. A Low Energy Barrier for Rotation Around Carbon-Carbon Double Bonds (with Y. Shvo and J. Bartulin), Tetrahedron Lett., 34, 3259 (1967).

146. Cyclizations of Anthraniliate-Acetylene Dicarboxylate Adducts. A Facile Route to 2,8-Dicarboalkoxy4(1브)-quinolinones (with N.D. Heindel), J. Org. Chem., 32, 3339 (1967).

147. Dimethyloxosulfonium 2-(Methylamino)benzolymethylide. A New Stable Ylide and Its Use in Heterocyclic Syntheses (with A.M. van Leusen), J. Org. Chem., 33, 66 (1968).

148. A New Method for C-5 Functionalization of Pyrimidines. New Routes to Azapteridines and Purines. Synthesis of Fervenulin (with F. Sowinski), J. Am. Chem. Soc., 90, 1374 (1968).

149. Cyclization Reactions of 2,2'-Disubstituted Biphenyls (with R.E. Buntrock), Chem. Revs. 68, 209 (1968).

150. An Unequivocal Synthesis of 6-Substituted Pteridine 8-Oxides, Pteridines, and 7,8-Dihydropteridines (with K. Lenard), J. Am. Chem. Soc., 90, 2424 (1968).

151. Thallium in Organic Synthesis. I. Alkylation and Acylation of B-Dicarbonyl Compounds (with G.H. Hawks, III and A. McKillop), J. Am. Chem. Soc., 20, 2421 (1968).

152. Thallium in Organic Synthesis. II. Acylation, Aroylation and Tosylation of Phenols and Carboxylic Acids (with G.W. McLay and A. McKillop), J. Am. Chem. Soc., 90, 2422 (1968).

153. Thallium in Organic Synthesis. III. Coupling of Aryl and Alkyl Grignard Reagents (with A. McKillop and L.F. Elsom), J. Am. Chem. Soc., 90, 2423 (1968).

154. Heterocyclic Syntheses from o-Aminonitriles. XXX. Synthesis of Some Diaza Steroids (with Y. Shvo), J. Org. Chem., 33, 1719 (1968). 
155. A New Route to Cyclic Azomethine Imides (with R.B. Greenwald), J. Am. Chem. Soc., 90, 5272 (1968).

156. Novel Heterocyclic Syntheses from Azomethine Imides. 2-Unsubstituted Diazetidinones (with R.B. Greenwald), J. Am. Chem. Soc., 90, 5273 (1968).

157. Further Studies on the Photochemical Reactions of 6-Substituted Phenanthridine 5-Oxides (with G.G. Spence), Chem. Commun., 1037 (1968).

158. Thallium in Organic Synthesis. IV. A Convenient One-Step Synthesis of Di-n-Alkylthallium(III) Bromides (with A. McKillop and L.F. Elsom), J. Organometal. Chem., 15, 500 (1968).

159. Acetylation of the Thallium(I) Salt of 2(1H)-Pyridone. Formation of N-Acetyl-2(1H)-Pyridone (Thallium in Organic Synthesis. VII), (with A. McKillop and M.J. Zelesko), Tetrahedron Lett., 48, 4945 (1968).

160. Thallium in Organic Synthesis. V. 9-Alkylation of Purines (with Y. Maki and A. McKillop), J. Org. Chem., 34, 1170 (1969).

161. Thallium in Organic Synthesis. VI. Synthesis of Primary Aliphatic Bromides (with A. McKillop and D. Bromley), J. Org. Chem., 34, 1172 (1969).

162. Thallium in Organic Synthesis. VIII. Preparation of Aromatic Bromides (with A. McKillop and D. Bromley), Tetrahedron Lett., 21, 1623 (1969).

163. Attempted Generation of Azacyclopropenones. A New Route to Nitriles (with A. Hassner, R.J. Isbister, R.B. Greenwald, and J.T. Klug), Tetrahedron, 25, 1637 (1969).

164. Structure and Total Synthesis of the Pyrimido[5,4-e]-as-Triazine Antibiotic, 2-Methylfervenulone (with F. Sowinski), J. Am. Chem. Soc., 21, 2143 (1969).

165. The Unequivocal Synthesis of Heterocyclic N-Oxides, in Topics in Heterocyclic Chemistry, R.N. Castle, ed., John Wiley \& Sons, Inc., New York, 1969, p. 1.

166. Thallium in Organic Synthesis. IX. Facile Thallation of Aromatic Compounds with Thallium(III) Trifluoroacetate (with A. McKillop, J.S. Fowler, M.J. Zelesko, J.D. Hunt and G. McGillivray), Tetrahedron Lett., 29, 2423 (1969).

167. Thallium in Organic Synthesis. X. A One-Step Synthesis of Aryl Iodides (with A. McKillop, J.S. Fowler, M.J. Zelesko, J.D. Hunt and G. McGillivray), Tetrahedron Lett., 29, 2427 (1969).

168. The Photochemical Reactions of Azoxy Compounds, Nitrones and Aromatic Amine N-oxides (with G.G. Spence and O. Buchardt), Chem. Revs., 70, 231 (1970).

169. Eindeutige Synthese von Pterin-carbaldehyd-(6) (with K. Lenard), Justus Liebigs Ann. Chem., 726, 100 (1969).

170. Photochemical Addition of Alcohols to an Amidine C=N Bond (with Y. Maki and B.E. Evans), J. Am. Chem. Soc., 91, 5181 (1969).

171. Thallium in Organic Synthesis. XI. Preparation of Azoxy Compounds (with A. McKillop and R.A. Raphael), J. Org. Chem., 35, 1670 (1970).

172. Photochemical Synthesis of Aromatic Chloro Compounds from Aromatic Iodo Compounds (with $F$. Kienzle), J. Org. Chem., 35, 528 (1970).

173. Thallium in Organic Synthesis. XII. Improved Syntheses of the 1-Acyloxy-2(1H)-pyridone Class of Active Esters (with F. Kienzle and A. McKillop), J. Org. Chem., 35, 1672 (1970). 
174. Thallium in Organic Synthesis. XIV. Orientation Control in an Electrophilic Aromatic Substitution Reaction (with F. Kienzle, R.L. Robey and A. McKillop), J. Am. Chem. Soc., 22, 2175 (1970).

175. Thallium in Organic Synthesis. XV. Synthesis of Phenols and Aromatic Nitriles (with H.W. Altland, R.H. Danforth, G. McGillivray and A. McKillop), J. Am. Chem. Soc., 22, 3520 (1970).

176. Thallium in Organic Synthesis (with A. McKillop), Accounts of Chemical Research, 3, 338 (1970).

177. A New, General and Unequivocal Pteridine Synthesis, in Chemistry and Biology of Pteridines (Folic Acid Included) (K. Iwai, M. Akino, M. Goto and Y. Iwanami, eds.), International Academic Printing Co., Ltd., Tokyo, 1970, pp. 79-93.

178. A New Synthesis of 6-Azapteridine Derivatives. The Reaction of 6-Amino-1,3-dimethyl-5-nitrosouracil with Acid Hydrazides, in Chemistry and Biology of Pteridines (Folic Acid Included), (with F. Yoneda, K. Ogiwara, M. Kanahori and S. Nishigaki), International Academic Printing Co., Ltd., Tokyo, 1970, pp. 145-153.

179. Syntheses von p-Chinonen mit Thallium(III)-trifluoroacetate (with A. McKillop, B.P. Swann and M.J. Zelesko), Angew. Chem., 82, 84 (1970).

180. Thallium in Organic Synthesis. XVI. Preparation of p-Quinones By Oxidation of Phenols and Hydroquinones with Thallium(III) Trifluoroacetate (with A. McKillop and B.P. Swann), Tetrahedron, 26, 4031 (1970).

181. Thallium in Organic Synthesis. XVII. Preparation of Biaryls from Arylmagnesium Bromides and Thallium(I) Bromide (with A. McKillop and L.F. Elsom), Tetrahedron, 26, 4041 (1970).

182. Thallium in Organic Synthesis. XVIII. Synthesis and Spectroscopic Studies of ArTlX 2 and $\mathrm{Ar}_{2} \mathrm{TIX}$ Compounds (with A. McKillop and J.D. Hunt), J. Organometal. Chem., 24, 77 (1970).

183. Thallium in Organic Synthesis. XIX. Photochemical Phenylation. An Effective Synthesis of Unsymmetrical Biphenyls from Arylthallium Di-trifluoroacetates (with F. Kienzle and A. McKillop), J. Am. Chem. Soc., 92, 6088 (1970).

184. A New Synthesis of as-Triazines and Pyrimido(4,5-e)-as-Triazines (6-Azapteridines) (with S.F. Martin), J. Org. Chem., 35, 3792 (1970).

185. Thallium in Organic Synthesis. XX. Oxidative Rearrangement of Olefins with Thallium(III) Nitrate: A Simple One-Step Synthesis of Aldehydes and Ketones (with A. McKillop, J.D. Hunt and F. Kienzle), Tetrahedron Lett., 60, 5275 (1970).

186. Thallium in Organic Synthesis. XXI. Direct Conversion of Chalcones into Benzils with Thallium(III) Nitrate (TTN) (with A. McKillop and B.P. Swann), Tetrahedron Lett., 60, 5281 (1970).

187. Photolysis of N-Alkoxy Quaternary Ammonium Salts: A Potential New Method of Aromatic Methoxylation (with J.D. Mee and D.W. Heseltime), J. Am. Chem. Soc., 92, 5814 (1970).

188. Thallium in Organic Synthesis. XXIV. A One-Step Synthesis of Aliphatic $\alpha$-Acyloxy Carboxylic Acids (with H.W. Altland, G. McGillivray and A. McKillop), Tetrahedron Lett., 60, 5285 (1970).

189. An Improved Synthesis of Phenyl Benzohydroxamate and Its Conversion to Phenyl O-Phenyl and OEthylbenzohydroxamate (with F. Kienzle), J. Org. Chem., 36, 233 (1971).

190. The Dimer of 2-Aminopyridine (with G.G. Spence), in "Organic Photochemical Syntheses", R. Srinivasan and T.D. Roberts, eds., Wiley-Interscience, New York, 1971, p. 46. 
191. 5-Phenylphenanthridine-6(5H)-one (with G.G. Spence), in "Organic Photochemical Syntheses", R. Srinivasan and T.D. Roberts, eds., Wiley-Interscience, New York, 1971, p. 89.

192. Pteridines. XXVI. Preparation and Properties of Some 3,4- and 5,6-Dihydropteridines (with M.J. Thompson, K. Perlman, R. Mengel and W. Pfleiderer), J. Org. Chem., 36, 4012 (1971).

193. Thallium in Organic Synthesis. XXII. Electrophilic Aromatic Thallation using Thallium(III) Trifluoroacetate. A Simple Synthesis of Aromatic Iodides (with A. McKillop, J.D. Hunt, M.J. Zelesko, J.S. Fowler, G. McGillivray and F. Kienzle), J. Am. Chem. Soc., 23, 4841 (1971).

194. Thallium in Organic Synthesis. XXIII. Electrophilic Aromatic Thallation. Kinetics and Applications to Orientation Control in the Synthesis of Aromatic Iodides (with F. Kienzle, R.L. Robey, A. McKillop and J.D. Hunt), J. Am. Chem. Soc., 23, 4845 (1971).

195. Thallium in Organic Synthesis. XXV. Electrophilic Aromatic Bromination using Bromine and Thallium(III) Acetate (with A. McKillop and D. Bromley), J. Org. Chem., 37, 88 (1972).

196. A Reinvestigation of Some Purported 1,2,4-Oxadiazines (with R.E. Buntrock), J. Org. Chem., 36, 634 (1971).

197. Condensation of Phosphonate Anions with 4-Amino-5-nitrosopyrimidines: A New Pteridine Synthesis (with B.E. Evans), Chem. Commun., 189 (1971).

198. The X-Ray Structures of 7-Aminofurazano(3,4-d)pyrimidine and 7-Amino-1,2,5-thiadiazolo(3,4d)pyrimidine (with E. Shefter and B.E. Evans), J. Am. Chem. Soc., 93, 7281 (1971).

199. A New, General Synthesis of 2-, 8-, and 9-Substituted Adenines (with G.P. Beardsley and Y. Maki), J. Org. Chem., 36, 3211 (1971).

200. Thallium in Organic Synthesis. XXVI. Direct Conversion of Oximes into Aldehydes and Ketones with Thallium(III) Nitrate (TTN) (with A. McKillop, J.D. Hunt and R.D. Naylor), J. Am. Chem. Soc., 93 , 4918 (1971).

201. Thallium in Organic Synthesis. XXVII. A Simple One-Step Conversion of Acetophenones into Methyl Phenylacetates using Thallium(III) Nitrate (TTN) (with A. McKillop and B.P. Swann), J. Am. Chem. Soc., 23, 4919 (1971).

202. Thallium in Organic Synthesis. XXVIII. Selective Oxidation of Acetylenes to Carboxylic Acids, Acyloins, Benzils, and Arylacetic Acids with Thallium(III) Nitrate (TTN) (with A. McKillop, O.H. Oldenziel, B.P. Swann and R.L. Robey), J. Am. Chem. Soc., 93, 7331 (1971).

203. A Novel Synthesis of Pyrimidopteridine-10-Oxides (with Y. Maki and M. Sako), Tetrahedron Lett., 4271 (1971).

204. Thallium in Organic Synthesis. XXIX. Photochemical Thiocyanation of Aromatic Compounds (with F. Kienzle and A. McKillop), Synthesis, 38 (1972).

205. Thallium in Organic Synthesis. XXX. A Facile Synthesis of 2-Alkynoic Esters (with R.L. Robey and A. McKillop), Angew. Chem. Int. Ed. Engl., 11, 48 (1972).

206. Thallium in Organic Synthesis. XXXI. Oxidative Cleavage of Glycols by Thallium Salts (with A. McKillop and R.A. Raphael), J. Org. Chem., 37, 4204 (1972).

207. Thallium in Organic Synthesis. XXXV. Oxidation of Cyclohexanones to Adipoins using Thallium(III) Nitrate (TTN) (with A. McKillop and J.D. Hunt), J. Org. Chem., 37, 3381 (1972).

208. Thallium in Organic Synthesis. XXXVI. A New Synthesis of Allenic Esters (with R.L.Robey and A. McKillop), J. Org. Chem., 32, 2797 (1972). 
209. The Novel Reaction of 1,3-Dimethyl-6-amino-5-nitrosouracil with Lead Tetraacetate (with Y. Maki and A. McKillop), J. Org. Chem., 37, 1601 (1972).

210. A Facile Method for Alkylation and Alkenylation of Heterocycles (with S.F. Martin), J. Am. Chem. Soc., 94, 2874 (1972).

211. Synthesis of Some 7-Aryl-6-azapteridines from 1,2,4-Triazine Intermediates (with S.F.Martin), J. Org. Chem., 37, 3958 (1972).

212. The Reaction of 5-Phenylazo-6-aminopyrimidines with Lead Tetraacetate. A Convenient Synthesis of 2-

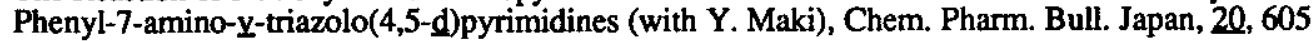
(1972).

213. Diphenylketene (with A. McKillop and G.H. Hawks), Org. Syn., 52, 36 (1972).

214. A Facile Synthesis of Quinine and Related Cinchona Alkaloids (with S.F. Martin), J. Am. Chem. Soc., 94, 6218 (1972).

215. A One-Step Synthesis of 7-Aryltheophyllines (with F. Yoneda), J. Org. Chem., 37, 4464 (1972).

216. Thallium in Organic Synthesis (with A. McKillop), Chemistry in Britain, 2, 4 (1973).

217. Pteridines. XXVII. A New Synthetic Route to Pteridines and 7-Azapteridines (with S.F. Martin, Y. Maki and G.P. Beardsley), J. Org. Chem., 38, 2238 (1973).

218. Pteridines. XXVIII. A New, General, and Unequivocal Pterin Synthesis (with K.L. Perlman, I.P. Sword, M. Sequin-Frey and P.A. Jacobi), J. Am.Chem. Soc., 25, 6407 (1973).

219. Pteridines. XXIX. An Unequivocal Route to 2,4-Diamino-6-substituted Pteridines (with K.L. Perlman, Y.-H. Kim, I.P. Sword and P.A. Jacobi), J. Am. Chem. Soc., 95, 6413 (1973).

220. Pteridines. XXX. A Facile Synthesis of Xanthopterin (with P.A. Jacobi), J. Am. Chem. Soc., 95, 4455 (1973).

221. Pteridines. XXXI. A New and Unequivocal Synthesis of Isoxanthopterin-6-carboxylic Acid (CyprinoPourpre B) (with R.F. Abdulla), Tetrahedron Lett., 2093 (1973).

222. Pteridines. XXXII. 2-Amino-3-cyano-5-chloromethylpyrazine 1-Oxide and its Conversion to 6-Alkenyl Substituted Pteridines (with T. Kobayashi), J. Org. Chem., 38, 2817 (1973).

223. A Convenient Synthesis of B-Halopyruvaldoximes (with R.C. Portnoy), J. Org. Chem., 38, 806 (1973).

224. A General Procedure for the Synthesis of Epoxy-Alkylated and Acylated Heterocycles (with M.L. Chittenden and S.F. Martin), Heterocycles, 1, 59 (1973).

225. Thallium in Organic Synthesis. XXXII. Oxidative Rearrangement of Olefins using Thallium(III) Nitrate (TTN) (with A. McKillop, J.D. Hunt, F. Kienzle and E. Bigham), J. Am. Chem. Soc., 25, 3635 (1973).

226. Thallium in Organic Synthesis. XXXIII. A One-Step Synthesis of Methyl Arylacetates from Acetophenones using Thallium(III) Nitrate (TTN) (with A. McKillop and B.P. Swann), J. Am. Chem. Soc., 95,3340 (1973).

227. Thallium in Organic Synthesis. XXXIV. Oxidations of Acetylenes with Thallium(III) Nitrate (TTN) (with A. McKillop, O.H. Oldenziel, B.P. Swann and R.L. Robey), J. Am. Chem. Soc., 25, 1296 (1973). 
228. Thallium in Organic Synthesis. XXXVII. A New Synthesis of Arylnitroso Compounds (with R.H. Danforth and A. McKillop), J. Org. Chem., 38, 2088 (1973).

229. Thallium in Organic Synthesis. XXXVIII. Oxidation of Chalcones, Deoxybenzoins, and Benzoins with Thallium(III) Nitrate (TTN) (with A. McKillop, B.P. Swann and M.E. Ford), J. Am. Chem. Soc., 25, 3641 (1973).

230. Recent Advances in Organothallium Chemistry (with A. McKillop), "Advances in Organometallic Chemistry", Vol. 11, F.G.A. Stone and R.West, eds., Academic Press, New York, 1973, pp. 147-206.

231. The Reaction of 6-Amino- and 6-Hydrazinopyrimidines with Diethyl Azodicarboxylate. A New Method of Carbon-5 Functionalization of Pyrimidines (with F. Sowinski), J. Org. Chem., 39, 907 (1974).

232. A Comment on the Acetoxythallation-Induced Lactonization of 2-endo Norbomenecarboxylic Acids (with A. McKillop and M.E. Ford), J. Org. Chem., 39, 2434 (1974).

233. An Unequivocal Total Synthesis of L-erythro-Biopterin (with P.A. Jacobi), J. Am. Chem. Soc., 96, 6781 (1974).

234. A General Method for Alkylation and Alkenylation of Heterocycles (with S.F. Martin), J. Am. Chem. Soc., 96, 8095 (1974).

235. Pteridines. XXXIV. The Synthesis of 8-Hydroxy-7(8H)-pteridinones (Pteridine Hydroxamic Acids) (with P.A. Jacobi), J. Org. Chem., 40, 2332 (1975).

236. Pteridines. XXXV. The Total Synthesis of Asperopterin B (with P.A. Jacobi and R.F. Abdulla), J. Org. Chem., 40, 2336 (1975).

237. Pteridines. XXXVI. Syntheses of Xanthopterin and Isoxanthopterin. Application of N-Oxide Chemistry to Highly Functionalized Pyrazines and Pteridines (with R.F. Abdulla, K. Tanaka and P.A. Jacobi), J. Org. Chem., 40, 2341 (1975).

238. Pteridines. XXXVIII. Synthesis of some 2,4-Diamino-6-substituted Methylpteridines. A New Route to Pteroic Acid (with R.C. Portnoy, D.C. Hochstetler and T. Kobayashi), J. Org. Chem., 40, 2347 (1975).

239. Synthesis of the Pyrimido(5,4-e) -as-triazine Antibiotics Fervenulin and 2-Methylfervenulone (MSD-92) (with F. Sowinski), J. Org. Chem., 40, 2321 (1975).

240. Synthesis of Isofervenulin and 2-Methylisofervenulone (with F. Sowinski), J. Org. Chem., 40, 2329 (1975).

241. Oxidation of 7-Aminothiadiazolo(3,4-d)pyrimidines and 7-Aminofurazano(3,4-d)pyrimidines by Xanthine Oxidase and Aldehyde Oxidase (with J.J. McCormack), Biochemical Pharmacology, 24, 1636 (1975).

242. Thallium in Organic Synthesis. XXXIX. A Convenient Synthesis of Nitroaryl Iodides (with H.W. Altland and A. McKillop), J. Org. Chem., 40, 3441 (1975).

243. Thallium in Organic Synthesis. XL. Preparation and Synthetic Utility of Diarylthallium Trifluoroacetates (with H.W. Altland and A. McKillop), J. Org. Chem., 40, 2351 (1975).

244. Thallium in Organic Synthesis. XLI. The Synthesis of 1-Substituted 2(1H)-Pyridones. A New Synthesis of Unsymmetrical Biphenyls (with H.W. Altland, F. Kienzle and A. McKillop), J. Org. Chem., 41, 24 (1976).

245. Thallium in Organic Synthesis. XIII. Direct Oxidation of 4-Substituted Phenols to 4,4-Disubstituted Cyclohexa-2,5-dienones Using Thallium(III) Nitrate (with A. McKillop, D.H. Perry, M. Edwards, S. Antus, L. Farkas and M. Nogradi), J. Org. Chem., 41, 282 (1976). 
246. 2-Iodo-p-xylene (with F. Kienzle and A. McKillop), Organic Syntheses, 55, 48 (1976).

247. 4,4'-Dimethyl-1,1'-biphenyl (with L.F. Elsom and A. McKillop), Organic Syntheses, 55, 48 (1976).

248. Methyl 2-Alkynoates from 3-Alkyl- or 3-Aryl-2-pyrazolin-5-ones (with R.L. Robey, D.K. Johnson and A. McKillop), Organic Syntheses, 55, 73 (1976).

239. Pteridines. XXXIX. Synthesis of 2,4-Diamino-7-alkenylpteridines and their 8-Oxides (with T. Kobayashi), J. Org. Chem., 41, 1299 (1976).

250. Pteridines. XXXVII. A Total Synthesis of L-erythro-Biopterin and Some Related 6-(Polyhydroxyalkyl)pterins (with P.A. Jacobi), J. Am. Chem. Soc., 98, 2301 (1976).

251. Thallium(III) Nitrate in Organic Synthesis: New Experimental Approaches to Oxythallation (with A. McKillop), Endeavor, 35, 88 (1976).

252. Thallium in Organic Synthesis. XLIII. Novel Oxidative Rearrangements with Thallium(III) Nitrate (TTN) in Trimethyl Orthoformate (TMOF) (with R.L. Robey, K.-T. Liu, B. Favre, H.T. Bozimo, R.A. Conley, C.-S. Chiang, A. McKillop and M.E. Ford), J. Am. Chem. Soc., 98, 3037 (1976).

253. Pteridine Synthesis, in "Chemistry and Biology of Pteridines", W. Pfleiderer, ed., Proceedings of the 5th International Symposium on Chemistry and Biology of Pteridines, Walter de Gruyter, Berlin, 1975.

254. Thallium in Organic Synthesis. XIIV. Oxidative Rearrangements via Oxythallation with Thallium(III) Nitrate Supported on Clay (with C.-S. Chiang, A. McKillop and J.F. White), J. Am. Chem. Soc., 98, 6750 (1976).

255. Thallium in Organic Synthesis. XLV. Synthesis of Aromatic Fluorides (with E.C. Bigham, D.K. Johnson and A. McKillop), J. Org. Chem., 42, 362 (1977).

256. Pteridines. XL. Some Reactions of 2-Amino-3-cyano-5-bromomethylpyrazine and 2-Amino-3-cyano-5methylpyrazine (with J.L. LaMattina), J. Org. Chem., 42, 1523 (1977).

257. Thallium in Organic Synthesis. 46. Oxidative Coupling of Aromatic Compounds Using Thallium(III) Trifluoroacetate. Synthesis of Biaryls (with A. McKillop and A.G. Turrell), J. Org. Chem., 42, 764 (1977).

258. Pteridines. 41. Synthesis and Dihydrofolate Reductase Inhibitory Activity of Some Cycloalka(g)pteridines (with J.V. Berrier, A.J. Cocuzza, R. Kobylecki and J.J. McCormack), J. Med. Chem., 20, 1215 (1977).

259. Pteridines. 42. Synthesis of Some Benzo(g)pteridines. A Novel Aromatization Reaction (with J.V. Berrier), Heterocycles, 6,449 (1977).

260. Trimethyl Orthoformate Absorbed upon the Montmorillonite Clay K-10: An Effective Reagent for Acetal and Ketal Formation (with C.-S. Chiang), Synthesis, 467 (1977).

261. Thallium in Organic Synthesis. 47. Regioselective Ring Expansion of Cyclic Aralkyl Ketones via WittigDerived Olefins with Thallium(III) Nitrate (TTN) (with C.-S. Chiang and A. McKillop), Tetrahedron Lett., 1827 (1977).

262. 2-Chloro-1,3-dithiane - A Formyl Cation Equivalent (with J.L. LaMattina), Tetrahedron Lett., 2077 (1977).

263. Thallium in Organic Synthesis. 48. Synthesis of ( \pm )-Ocoteine by Non-Phenolic Coupling with TTFA (with J.G. Andrade and A. McKillop), Chem. Commun., 538 (1977). 
264. Preparation of 3,4,5-Trisubstituted Pyrazoles from 2,2-Dioxoketene-S,S-acetals (with W.R. Purdum), Heterocycles, 6, 1865 (1977).

265. Pteridines. 43. A Facile Synthesis of 6-Chloropterin and 2,4-Diamino-6-chloropteridine (with R. Kobylecki), J. Org. Chem., 43, 680 (1978).

266. Synthesis of $\gamma$ and $\delta$-(1,3-Dithianyl)-B-ketoesters (with J.L. LaMattina), J. Org. Chem., 43, 1200 (1978).

267. Pteridines. 44. A Convenient Synthesis of 6-Formylpterin (with R.N. Henrie II and R.C. Portnoy), J. Org. Chem., 43, $736(1978)$.

268. Thallium in Organic Synthesis. 49. Oxidative Rearrangement of Chalcone Dimethylketals to Methyl 2,3Diaryl-3-methoxypropanoates with Thallium(III) Nitrate (TTN) in Trimethyl Orthoformate (TMOF) (with R.A. Conley, D.K. Johnson and A. McKillop), J. Org. Chem., 42, 4167 (1977).

269. Thallium in Organic Synthesis. 51. Oxidation of Enolizable Ketones to $\alpha$-Nitrato Ketones by Thallium(III) Nitrate (TTN) in Acetonitrile (with A. McKillop, D.W. Young, M. Edwards and R.P. Hug), J. Org. Chem., 43, 3773 (1978).

270. Thallium in Organic Synthesis. 50. A Convenient Synthesis of Thallium(I) Cyanide, A Useful Reagent in Organic Synthesis (with J.G. Andrade, K.C. John and A. McKillop), J. Org. Chem., 43, 2280 (1978).

271. Pteridines. 45. Synthesis and Properties of Some Isothiazolo(4,5-b $)$ pyrazines and Isothiazolo(4,5g)pteridines (with E. Wachsen), J. Org. Chem., 43, 4154 (1978).

272. Synthesis and Properties of 1,3-Dimethyl-6-azalumazines (Isofervenulines) (with F. Yoneda, T. Nagamatsu, K. Ogiwara, M. Kanahori and S. Nishigaki), Chem. Pharm., Bull. (Tokyo), 26, 367 (1978).

273. Thallium in Organic Synthesis. 52. Oxidations of 3-(Alkoxyaryl)propionic Acids by Thallium-(III) Trifluoroacetate: Synthesis of Dihydrocoumarins, Spirocyclohexadienone-lactones, and p-Benzoquinones (with J.G. Andrade, G.J.H. Rall and A. McKillop), J. Org. Chem., 43, 3632 (1978).

274. Thallium in Organic Synthesis. 53. Simple Procedures for the Replacement of a Phenolic OH Group by. $\mathrm{N}=\mathrm{NAr}, \mathrm{N}=\mathrm{O}, \mathrm{H}, \mathrm{NH}_{2}$ and $\mathrm{C}$ Substituents (with G.E. Jagdmann, Jr. and A. McKillop), J. Org. Chem., 43, 4385 (1978).

275. Thallium in Organic Synthesis. 55. Oxidative Dimerization of 4-Alkoxycinnamic Acids to 2,6-Diaryl3,7-dioxobicyclo[3.3.0]-octane-4,8-diones with Thallium(III) Trifluoroacetate (TTFA) (with J.G. Andrade, G.J.H. Rall and A. McKillop), Tetrahedron Lett., 3623 (1978).

276. A Convenient Synthesis of B-Ketoesters (with I.J. Turchi), Org. Prep. Proc. Int., 10, 221 (1978).

277. O-Phenylation of 6-Amino-5-nitroso-1,3-dimethyluracil with Diphenyliodonium Chloride. A New Route to Lumazines (with M. Inbasekaran), Heterocycles, 10, 37 (1978).

278. Base-Catalyzed Ring Contraction of 6-Imino-5-phenoxyimino-1,3-dimethyluracil to 1,3-Dimethyl-4,5diiminoimidazolidin-2(1H)-one (with M. Inbasekaran), Heterocycles, 10, 45 (1978).

279. Some Isomers and Analogs of Pteridine Natural Products and Chemotherapeutic Agents (with R.N. Henrie II and D.J. Dumas) in Chemistry and Biology of Pteridines (R.L. Kisliuk and G.M. Brown, eds.), Elsevier/North-Holland, New York, N.Y., 1978, pp. 71-75. 
280. Studies on the Synthesis of Urothione and Deoxyurothione (with L.A. Reiter) in Chemistry and Biology of Pteridines (R.L. Kisliuk and G.M. Brown, eds.), Elsevier/North Holland, New York, N.Y., 1978, pp. $77-80$.

281. Thallium in Organic Synthesis. 54. Reactions of Reissert Compounds with Thallium(III) Nitrate (TTN) (with I.J. Turchi and A. McKillop), Heterocycles, 11, 481 (1978).

282. Pteridines. 46. Unequivocal Synthesis of 2,4-Diamino-6 $(5 \mathrm{H})$-pteridinone (4-Amino-4-deoxyxanthopterin) and Xanthopterin from 5,7-Diaminofurazano(3,4-d)pyrimidine (with A.J. Cocuzza), J. Org. Chem., 44, 302 (1979).

283. Synthesis and Properties of 7-Azaxanthopterin (with A.J. Cocuzza), J. Org. Chem., 44, 1125 (1979).

284. 1,5-Dipolar Cyclization Reactions (Electrocyclic Reactions of 1,5-Dipoles) (with I.J. Turchi), Chem. Revs., 79, 181 (1979).

285. Pteridines. 47. Preparation and Chemistry of 2-Amino-6-carbalkoxy-3-cyano-5-substituted Pyrazine 1Oxides: Synthesis of Pterin-6-carboxaldehyde (with D.J. Dumas), J. Org. Chem., 45, 2485 (1980).

286. New Methods in Heterocyclic Chemistry in "Annual Reports of Medicinal Chemistry", Vol. 14 (H.-J. Hess, ed.), Academic Press, New York, N.Y., 1979, pp. 278-287.

287. Heterocyclization with Cyano and Sulfonyl Epoxides. Preparation of Quinoxalines and Tetrahydroquinoxalines (with C.A. Maryanoff and J.S. Skotnicki), J. Org. Chem., 45, 2512 (1980).

288. Thallium in Organic Synthesis. 56. A Novel Oxidative Intramolecular Cyclization/Rearrangement of 5Norbornen-trans-2,3-dicarboxylic Acid with Thallium(III) Trifluoroacetate (TTFA) (with G.E. Jagdmann, Jr. and A. McKillop), J. Org. Chem., 45, 3373 (1980).

289. Thallium in Organic Synthesis. 57. The Reaction of Chalcones and Chalcone Ketals with Thallium(III) Trinitrate (TTN) (with R.A. Conley, D.K. Johnson, A. McKillop, and M.E. Ford), J. Org. Chem., 45, 3433 (1980).

290. Thallium in Organic Synthesis. 58. Regiospecific Intermolecular Oxidative Dehydrodimerization of Aromatic Compounds to Biaryls Using Thallium(III) Trifluoroacetate (with A. McKillop, A.G. Turrell, and D.W. Young), J. Am. Chem. Soc., 102, 6504 (1980).

291. Thallium in Organic Synthesis. 59. Alkaloid Synthesis via Intramolecular Nonphenolic Oxidative Coupling. Preparation of $( \pm)$-Ocoteine, $( \pm)$-Acetoxyocoxylonine, $( \pm)$-3-Methoxy-N-acetylnomantenine, $( \pm)$-Neolitsine, $( \pm)$-Kreysigine, $( \pm)$-O-Methyl Kreysigine, and $( \pm)$-Multifloramine (with J.G. Andrade, G.J.H. Rall, and A. McKillop), J. Am. Chem. Soc., 102, 6513 (1980).

292. A New Synthesis of Aminomalononitrile Tosylate (with J.H. Sun), Synthesis, 10, 801 (1980).

293. Pteridines. 48. Utilization of 3,3-dimethoxy-2-pyrrolidinopropene for the Synthesis of Folic Acid, N2'Acetyl-7-folic Acid, and 5-Deaza-7-folic Acid (with D.J. Dumas), J. Org. Chem., 46, 1394 (1981).

294. Synthesis and Reactions of Novel 3-Oxo-1,2-Diazetidinium Ylides (with R.B. Greenwald, N.F. Haley, H. Yanagisawa and R.J. Clemens), "Organic Synthesis Today and Tomorrow" (B.M. Trost and C.R. Hutchinson, eds.), Pergamon Press, Oxford, 1981, pp. 173.

295. Thallium in Organic Synthesis. 60. 2,6-Diaryl-3,7-dioxabicyclo(3.3.0)octane-4,8-dione Lignans by Oxidative Dimerization of 4-Alkoxycinnamic Acids with Thallium(III) Trifluoroacetate or Cobalt(III) Trifluoride (with J.G. Andrade, G.J.H. Rall, K. Steliou, G.E. Jagdmann, Jr., and A. McKillop), J. Org. Chem., 46, 3078 (1981).

296. A Convenient Synthesis of 1-Aryl-4-piperidones (with J.S. Skotnicki), Synthesis, 8, 606 (1981). 
297. Thallium in Organic Synthesis. 61. Intramolecular Capture of Radical Cations from Thallium(III) Trifluoroacetate Oxidation of Arylalkanoic Acids and Arylalkanols. New Routes to Oxygen Heterocycles (with J.G. Andrade, G.J.H. Rall, I.J. Turchi, K. Steliou, G.E. Jagdmann, Jr., and A. McKillop), J. Am. Chem. Soc., 103, 6856 (1981).

298. Formation of Monocyclic and Bicyclic Aza-ß-lactams and Other Novel Heterocycles from 1-(Diphenylmethylene)-3-oxo-1,2-diazetidinium Inner Salt (with R.J. Clemens, H.M.L. Davies, and N.F. Haley), J. Am. Chem. Soc., 103, 7659 (1981).

299. 3-Oxo-1,2-diazetidinium Tosylate (with H.M.L. Davies, R.J. Clemens, H. Yanagisawa and N.F. Haley), J. Am. Chem. Soc., 103, 7660 (1981).

300. Unequivocal Synthesis of Euglenapterin (with P.A. Jacobi and M. Martinelli), J. Org. Chem., 46, 5416 (1981).

301. Synthesis and Properties of 3-Oxo-1,2-diazetidinium Ylides (with N.F. Haley and R.J. Clemens), J. Am. Chem. Soc., 103, 7743 (1981).

302. Pteridines. 49. Synthesis of 2,4-Diamino-6,8-dihydro-7-aryl-8-oxopyrrolo[3,4-g]pteridines (with D.J. Dumas), J. Org. Chem., 47, 116 (1982).

303. Pteridines. 50. Unequivocal Total Synthesis of Deoxyurothione (with L.A. Reiter), J. Org. Chem., 47, 528 (1982).

304. Conversion of a Primary Amino Group into a Nitroso Group. Synthesis of Nitroso-Substituted Heterocycles (with C.-P. Tseng and J.B. Rampal), J. Org. Chem., 47, 552 (1982).

305. Nucleophilic Displacement of Primary Amino Groups via 1-Substituted 4-Tosylimidazoles (with J.L. LaMattina and C.-P. Tseng), J. Org. Chem., 47, 2043 (1982).

306. Compounds of Thallium in Organic Synthesis (with A. McKillop), "Comprehensive Organometallic Chemistry", (Sir G. Wilkinson, F.G.A. Stone and E.W. Abel, eds.), Pergamon Press, Oxford, England, 1982, Vol. 7, p. 465.

307. Synthetic Methods in Pteridine Chemistry: Some Applications to Pteridine Natural Products, Chemistry and Biology of Pteridines, (J.A. Blair, ed.), Walter de Gruyter \& Co., Berlin, N.Y., 1983, pp. 23-49.

308. Synthesis and Biological Activity of 5-Deazafolic Acid and 5-Deazaaminopterin, Chemistry and Biology of Pteridines, (J.A. Blair, ed.), Walter de Gruyter \& Co., Berlin, New York, 1983, pp. 115-119.

309. Rhodium(II) Acetate-Catalyzed Reaction of Ethyl 2-Diazo-3-oxopent-4-enoates: Simple Routes to 4-Aryl2-hydroxy-1-naphthoates and $\beta, \gamma$-Unsaturated Esters. The Dianion of Ethyl 4-

(Diethylphosphono)acetoacetate as a Propionate Homoenolate Equivalent (with H.M.L. Davies), Tetrahedron Lett., 24, 5453 (1983).

310. Synthesis and Biological Activity of L-5-Deazafolic Acid and L-5-Deazaaminopterin: Synthetic Strategies to 5-Deazapteridines (with D.C. Palmer, T.J. George, S.R. Fletcher, C.-P. Tseng, P.J. Harrington and G.P. Beardsley), J. Org. Chem., 48, 4852 (1983).

311. Improved Synthesis of 1,5-bis(Dimethylamino)-1,4-pentadien-3-one (with J. Skotnicki), Syn. Commun., 13,1137 (1983).

312. Synthesis of Cyclic Azomethine Imines from Aza-B-Lactams. Conversion of 3-Oxo-1,2-diazetidinium Tosylates into 1-Substituted 3-Oxo-1,2-diazetidinium Inner Salts (with R.J. Clemens and H.M.L. Davies), J. Org. Chem., 48, 4567 (1983). 
313. Approaches to the Synthesis of Aza Analogues of the B-Lactam Antibiotics: Some Anomalous Rhodium(II)-Catalyzed Carbene Insertion Reactions (with H.M.L. Davies), J. Org. Chem., 49, 113 (1984).

314. Thallium in Organic Synthesis. 62. A Convenient Synthesis of $\alpha$-Arylsuccinic Acids (with R.A. Conley, A.H. Katz and A. McKillop), J. Org. Chem., 49, 3840 (1984).

315. N-vs. O-Acylation of 1,2-Diazetidin-3-one: 4,5-Dihydro-1,3-oxadiazin-6-ones by Ring Enlargement (with H.M.L. Davies, W.T. Lavell and N.D. Jones), J. Org. Chem., 49, 2204 (1984).

316. Synthesis of 1-(p-Carbomethoxyphenyl)-3-pyrrolidinone by a Diels-Alder Route (with K.McDaniel), J. Org. Chem., 49, 2500 (1984).

317. Synthesis and Reactions of Some 1-Substituted 1,2-Diazetidinones (with H.M.L. Davies), J. Org. Chem., 49 , 4415 (1984).

318. A Convenient Synthesis of t-Butyl p-Aminobenzoate (with S.R. Fletcher and A.L. Sabb), Syn. Commun., 14,4415 (1984).

319. Thallium in Organic Synthesis. 63. A Convenient Synthesis of Aromatic Nitriles (with A.H. Katz and A. McKillop), Tetrahedron Lett., 25, 5473 (1984).

320. The Condensation of 2,4-Diamino-6(1H)-pyrimidinone with 2-Aminomethylenecyclopentanone: A Correction (with S.R. Fletcher), J. Org. Chem., 49, 3226 (1984).

321. Synthesis of 4-Amino-4-deoxy-7,10-methano-5-deazapteroic Acid and 7,10-Methano-5-deazapteroic Acid (with S.R. Fletcher and S. Fitzjohn), J. Org. Chem., 50, 1010 (1985).

322. Synthesis of D,L-Ethano-5-deazaaminopterin and L-7,10-Ethano-5-deazafolic Acid (with J. Skotnicki and S.R. Fletcher), J. Org. Chem., 50, 1005 (1985).

323. Thallium(III) Salts as Oxidants in Organic Synthesis (with A. McKillop), in "Organic Syntheses by Oxidation with Metal Compounds", (W. J. Mijs and C. R. H. I. de Jonge, eds), Plenum Press, 1986, pp. 695-736.

324. Synthesis of Ethy1 7,10-Ethano-4-amino-4-deoxypteroate (with J. Skotnicki and D.J. Dumas), Heterocycles, $\underline{23}, 1703$ (1985).

325. Efficient Synthesis of 5-Substituted-4,5-Dihydro-1,2,4-triazine-6-ones and 5-Substituted 1,2,4-triazine-6ones (with J.E. Macor), J. Het. Chem., 22, 409 (1985).

326. The Directing Ability of the Methylthio Substituent in Lithiation Reactions of Thiophenes (with D.E. Vogel), J. Org. Chem., $\underline{50}$, 1002 (1985).

327. Synthesis of the Antileukemic Agents 5,10-Dideazaaminopterin and 5,10-Dideaza-5,6,7,8tetrahydroaminopterin (with P.J. Harrington, S.R. Fletcher, G.P. Beardsley and R. G. Moran), J. Med. Chem., 28, 914 (1985).

328. 5,10-Dideaza-5,6,7,8-tetrahydrofolic Acid (DDATHF), A Potent Antifolate Inhibitory to de novo Purine Synthesis (with Richard G. Moran and G. Peter Beardsley), Proc. Amer. Assoc. Cancer Res., 26, 231 (1985).

329. Thallium in Organic Synthesis. 64. Electrophilic Thallation of Electron-Rich Arenes (with A.H. Katz, S.I. Alvarado and A. McKillop), J. Organomet. Chem., 285, C9-C12 (1985).

330. An Unusually Facile Diels-Alder Reaction with Novel 6-Alkylthio Derivatives of 1,2,4-Triazine (with J.E. Macor), Tetrahedron Lett., 26, 2415 (1985). 
331. Novel Intramolecular Diels-Alder Reactions with Alkynylthio Derivatives of 1,2,4-Triazines. New Routes to Thieno(2,3-b)pyridines and Thieno(2,3-c)pyridines (with J.E. Macor), Tetrahedron Lett., 26, 2419 (1985).

332. Thallium in Organic Synthesis. 65. A Novel Synthesis of Benzoxazoles from Anilides (with A.H. Katz, S.I. Alvarado and A. McKillop), J. Org. Chem., 51, 1607 (1986).

333. Thallium in Organic Synthesis. 67. Intramolecular Capture of Aromatic Radical Cations by an N-Tosyl Group (with A. McKillop and H.M.L. Davies), Syn. Commun. 16, 267 (1986).

334. Thallium in Organic Synthesis. 68. A Convenient Synthesis of 2-Phenylindoles from Anilides (with A.H. Katz, H. Salgado-Zamora and A. McKillop), Tetrahedron Lett., 26, 5963 (1985).

335. Unusual Hydrolysis of 2-Nitrosopyridines: Formation of 1-(2'-Pyridyl)-2(1H)-pyridones (with K.A. Harrison and J.B. Rampal), J. Org. Chem., 51, 101 (1986).

336. Thietane Alkylations. A General Synthesis of 3-Halopropyl Benzyl Sulfides (with D.C. Palmer), J. Org. Chem., 51, 846 (1986).

337. Synthesis and Reactions of Some 1,2-Disubstituted 1,2-Diazetidin-3-ones: An Intramolecular Aldol Approach to Bicyclic Systems (with H.M.L. Davies and J.S. Hinkle), J. Org. Chem., 51, 1530 (1986).

338. Synthesis of Fused 1,2-Diazetidinones via an Intramolecular Homer-Emmons Reaction (with H.M.L. Davies), J. Org. Chem., 51, 1537 (1986).

339. Further Intramolecular Reactions of 1,2,4-Triazines. Synthesis of Furo(2,3-b)pyridines and Dihydropyrano(2,3-b)pyridines (with J.E. Macor), Tetrahedron Lett., 27, 431 (1986).

340. Intramolecular Diels-Alder Reactions of 1,2,4-Triazines: Synthesis of Tricyclic Condensed Pyridines and Pyrazines (with L. G. French), Tetrahedron Lett., 27, 1967 (1986).

341. Intramolecular Diels-Alder Reactions of 1,2,4-Triazines: Exploitation of the Thorpe-Ingold Effect for the Synthesis of 2,3-Cyclopentenopyridines and 5,6,7,8-Tetrahydroquinolines (with J. E. Macor), Tetrahedron Lett., 27, 2107 (1986).

342. Pterin and Folate Chemistry, in "Chemistry and Biology of Pteridines" (B. A. Cooper and V. M. Whitehead, eds), Walter de Gruyter \& Co., Berlin, p. 55 (1986).

343. Synthesis of 5,10-Dideaza-5,6,7,8-Tetrahydrofolic Acid (DDATHF) and Analogs (with G. S. K. Wong, S. R. Fletcher, P. J. Harrington, G. P. Beardsley and C. J. Shih), in "Chemistry and Biology of Pteridines" (B. A. Cooper and V. M. Whitehead, eds), Walter de Gruyter \& Co., Berlin, p. 61 (1986).

344. Deaza Derivatives of Tetrahydrofolic Acid. A New Class of Folate Antimetabolite (with G.P. Beardsley, G.B. Grindey and R.G. Moran), in "Chemistry and Biology of Pteridines" (B.A. Cooper and V.M. Whitehead, eds.), Walter de Gruyter \& Co., Berlin, p. 953 (1986).

345. A New Class of Antifolates. 5,10-Dideazatetrahydrofolic Acid (DDATHF), an Inhibitor of GAR Transformylase with Broad in vivo Activity (with G. Peter Beardsley, C. Shih, G. A. Poore, G. B. Grindey and Richard G. Moran), Proc. Amer. Assoc. Cancer Res., 27, 259 (1986).

346. Some New Methods for Preparing 2,3- and 3,4-Diaminopyridines (with J. B. Campbell, J. M. Greene, E. R. Lavagnino, D. N. Gardner, A. J. Pike and J. Snoddy), J. Heterocycl. Chem., 23, 669 (1986).

347. A Novel 'Ring-Switching' Amination: Conversion of 4-Amino-5-cyanopyrimidine to 4,6-Diamino-5cyanopyrimidine (with W.A. Ehrhart, C.O.S. Tomlin and J.B. Rampal), Heterocycles, 25, 343 (1987). 
348. Further Intramolecular Diels-Alder Reactions of 1,2,4-Triazines. Synthesis of Dihydropyrrolo(2,3b)pyridines (with J.L. Pont), Tetrahedron Lett., 28, 379 (1987).

349. Diels-Alder Reactions of Bicyclic 1,2,4-Triazines. The Conversion of Pyrimido[4,5-e]-1,2,4-triazines to Pyrido[2,3-d]pyrimidines (5-Deazapteridines) (with K. F. McDaniel and J. C. Warner), Tetrahedron Lett.,28, 1977 (1987):

350. The Two Diastereomers of 5,10-Dideazatetrahydrofolate are Equiactive (with R. G. Moran, C. Shih and G. P. Beardsley), Proc. Am. Assoc. Cancer Res., 28, 274 (1987).

351. Intramolecular Diels-Alder Reactions of 1,2,4-Triazines. A Facile Synthesis of Thieno[2,3-b]pyridines and 2,3-Dihydro-2H-thiopyrano[2,3-b]pyridines (with J. E. Macor), J. Org. Chem., 52, 4280 (1987).

352. Intramolecular Diels-Alder Reactions of 1,2,4-Triazines. Synthesis of Condensed Pyrimidines (with J. L. Pont), J. Org. Chem., 52, 4287 (1987).

353. New Routes to 1,2-Diazetidin-3-ones (with J. S. Hinkle), J. Org. Chem., 52, 4107 (1987).

354. Pteridines. 51. A New and Unequivocal Route to C-6 Carbon-Substituted Pterins and Pteridines (with $P$. S. Ray), J. Org. Chem., 52, 3997 (1987).

355. Synthesis and Structural Confirmation of 5,6-Cyclopenteno-5-deazapterin (with J. C. Warner), Heterocycles, 26, 2673 (1987).

356. Pteridines. 52. A Convenient Synthesis of 6-Formylpterin (with P. S. Ray), Syn. Commun., 17, 1865 (1987).

357. Intramolecular Diels-Alder Reactions of 1,2,4-Triazines. A General Synthesis of Furo[2,3-b]pyridines, 2,3-Dihydropyrano[2,3-b]pyridines and Pyrrolo[2,3-b]]pyridines (with J. E. Macor and J. L. Pont), Tetrahedron, 43, 5145 (1987).

358. Heterodienophilic Intramolecular Diels-Alder Reactions of 1,2,4-Triazines. Synthesis of Novel Polycyclic Condensed Pyrazines and Lumazines (with J. L. Pont and J. C. Warner), Tetrahedron, 43, 5159 (1987).

359. Pteridines. 53. A Convenient Synthetic Approach to 10-Deazaaminopterin and 10-Deazafolic Acid (with P. S. Ray), J. Org. Chem., 53, 35 (1988).

360. Intramolecular Diels-Alder Reactions of 6-Azalumazines and 6-Azapterins. A Facile Route to 6,7Annulated-5-deazapteridines (with J. L. Pont and J. C. Warner), J. Org. Chem., 53, 800 (1988).

361. A Convenient Synthesis of 6-Formyl-5-deazapterin (with C.-m. Yoon), Syn. Commun., 18, 1187 (1988).

362. Diels-Alder Reactions of 7-Azalumazines. Synthesis of Condensed Lumazines and 8-Deazalumazines (with J. L. Pont and J. C. Warner), J. Org. Chem., 53, 3568 (1988).

363. Diels-Alder Reactions of 6-Azapterins. An Alternative Strategy for the Synthesis of 5,10-Dideaza5,6,7,8-tetrahydrofolic Acid (DDATHF) (with P. M. Harrington and J. C. Warner), Heterocycles, 27 , 1925 (1988).

364. Synthesis of Analogues of Folic Acid, Aminopterin and Methotrexate as Antitumour Agents (with D. C. Palmer and J. S. Skotnicki), in "Progress in Medicinal Chemistry", Vol. 25 (G. P. Ellis, ed), Elsevier, Amsterdam, 1988, pp. 85-231.

365. Synthesis of 2-Amino-6,7-dihydrothieno[3',2':5,6]pyrido[2,3-d]pyrimidin-4-one (with J. L. Pont and J. C. Warner), J. Heterocyclic Chem., 25, 1733 (1988). 
366. Competitive Intramolecular Diels-Alder Reaction and Intramolecular Coplanar Cycloamination of 3-(3Butynylthio)-1,2,4-triazin-5-ones (with J. L. Pont, D. van Engen, and J. C. Warner), J. Org. Chem., 53, 5093 (1988).

367. Studies on the Molybdenum Cofactor. Model Synthetic Routes Directed at Form B (with A. L. Sabb), J. Org. Chem., 53, 5839 (1988).

368. Synthesis of a Novel Tetrahydrothieno[2,3-b]pyrrole (with S. R. Fletcher, C.McCarthy, V. Cody, and R. J. Kempton), J. Org. Chem., 53, 6118 (1988).

369. Electrochemistry of the Anticancer Agents Methotrexate and alpha-Difluoromethylomithine in Iminium Form (with P. Kovacic, J. R. Ames, and M. D. Ryan), J. Pharm. Sci, 77, 999 (1988).

370. Novel Cycloaddition Routes to Fused Heterocycles, Bull. Soc. Chim. Belges, 27, 599 (1988).

371. Biochemical Determinants of Sensitivity and Resistance to 5,10-Dideaza-5,6,7,8-tetrahydrofolic acid, DDATHF, in CCRF-CEM Cells (with G. Pizzarno, B. A. Moroson, A. R. Cashmore, and G. P. Beardsley), Proc. Am. Assoc. Cancer Res., 29, 281 (1988).

372. A New Folate Antimetabolite, 5,10-Dideaza-5,6,7,8-tetrahydrofolate, is a Potent Inhibitor of de novo Purine Synthesis (with G. P. Beardsley, B. A. Moroson, and R. G. Moran), J. Biol. Chem., 264, 328 (1989).

373. Studies on the Molybdenum Cofactor. An Unequivocal Total Synthesis of ( \pm )-Urothione (with L. A. Reiter), J. Am. Chem. Soc., 111, 285 (1989).

374. Synthesis of Pyridines by Diels-Alder Reactions of Heterosubstituted 1,2,4-Triazines with Enamines and an Enaminone (with J. E. Macor), J. Org. Chem., 54, 1249 (1989).

375. Intramolecular Diels-Alder Reactions of 1,2,4-Triazines. Routes to Condensed Pyrazines via Cycloaddition of Nitrile Dienophiles (with L. G. French), J. Org. Chem., 54, 1245 (1989).

376. Synthesis and Competitive Thermal Transformations of 3-[2'-(2-Propynylthio)anilino]-1,2,4-triazines (with J. L. Pont and J. C. Wamer), J. Org. Chem., 54, 1456 (1989).

377. A Facile Route to "Open-Chain" Analogues of DDATHF (with P. M. Harrington and C. Shih), Heterocycles, 28, 1169 (1989).

378. Synthesis and Antitumor Activity of 5-Deaza-5,6,7,8-tetrahydrofolic Acid (5-DATHF) and $\mathrm{N}^{10}$ Substituted Analogues (with J. M. Hamby, C. Shih, G. B. Grindey, S. M. Rinzel, G. P. Beardsley and R. G. Moran), J. Med. Chem., 32, 1517 (1989).

379. Convergent and Efficient Palladium-Effected Synthesis of 5,10-Dideaza-5,6,7,8-tetrahydrofolic Acid (DDATHF) (with George S. K. Wong), J. Org. Chem., 54, 3618 (1989).

380. Diels-Alder Reactions of 1,2,4-Triazines. Synthesis of Thieno[2,3-c]pyridines and 3,4-Dihydro-2Hthiopyrano[2,3-c]pyridines from 6-(Alkynylthio)-1,2,4-triazines (with J. E. Macor), J. Org. Chem., 54, 4984 (1989).

381. Studies on the Molybdenum Cofactor. Determination of the Structure and Absolute Configuration of Form A (with P. S. Ray, I. S. Darwish, J. L. Johnson and K. V. Rajagopalan), J. Amer. Chem. Soc., 111, 7664 (1989).

382. New Pathways from Pteridines. Design and Synthesis of a New Class of Potent and Selective Antitumor Agents, Lectures in Heterocyclic Chemistry, J. Heterocyclic Chem., 27, 1 (1990) 
383. The 6-S and 6-R Diastereomers of 5,10-Dideaza-5,6,7,8-tetrahydrofolate are Equiactive Inhibitors of de novo Purine Synthesis (with R. G. Moran, S. W. Baldwin, and C. Shih), J. Biol. Chem., 264, 21047 (1989).

384. A Convergent Synthesis of 5,10-Dideaza-5,6,7,8-tetrahydrofolic Acid (DDATHF) and 5,10-Dideaza5,6,7,8-tetrahydrohomofolic Acid (HDDATHF). An Effective Principle for Carbonyl Group Activation (with P. M. Harrington), J. Org. Chem., 55, 3222 (1990).

385. Synthetic Studies on the Molybdenum Cofactor (with P. S. Ray, I. Darwish and R. Dötzer), Chemistry and Biology of Pteridines, H.-Ch. Curtius, S. Ghisla and N. Blau, eds., Walter de Gruyter \& Co., Berlin, New York, 1989, pp. 67-72.

386. New Synthetic Studies on Deazafolates (with Z.-y. Chang, P. M. Harrington, J. M. Hamby, M. Papadopoulou, J. C. Warner, G. S. K. Wong, C.-m. Yoon, and C. Shih), Chemistry and Biology of Pteridines, H.-Ch. Curtius, S. Ghisla and N. Blau, eds., Walter de Gruyter \& Co., Berlin, New York, 1989, pp. 987-994.

387. Inhibition of de novo Purine Synthesis of Deazatetrahydrofolates (with R. G. Moran, S. W. Baldwin and C. Shih), Chemistry and Biology of Pteridines, H.-Ch. Curtius, S. Ghisla and N. Blau, eds., Walter de Gruyter \& Co., Berlin, New York, 1989, pp. 1080-1085.

388. Molecular Modelling Studies on Deazatetrahydrofolates (with C. Shih, G. B. Grindey, R. G. Moran and P. M. Harrington), Chemistry and Biology of Pteridines, H.-Ch. Curtius, S. Ghisla and N. Blau, eds., Walter de Gruyter \& Co., Berlin, New York, 1989, pp. 995-1000.

389. Synthesis and Structure-Activity Relationship Studies of 5,10-Dideazatetrahydrofolic Acid (DDATHF) (with C. Shih, G. B. Grindey, L. S. Gossett, R. G. Moran, and P. M. Harrington), Chemistry and Biology of Pteridines, H.-Ch. Curtius, S. Ghisla and N. Blau, eds., Walter de Gruyter \& Co., Berlin, New York, 1989, pp. 1035-1038.

390. Reduced Folate Analogs as Inhibitors of de Novo Purine Biosynthesis (with G. P. Beardsley, G. Pizzarno, A. Cross, O. Russello, F. Hajjar, D. Wildman, J. A. Sokoloski, B. A. Moroson, A. Cashmore, C. Shih and G. B. Grindey, Pteridines, 2, 37 (1990).

391. Intramolecular Diels-Alder Reactions of 1,2,4-Triazines. Synthesis of 2,3-Cyclopentenopyridines and 5,6,7,8-Tetrahydroquinolines (with J. E. Macor and L. G. French), J. Org. Chem., 56, 1807 (1991).

392. Pteridines. 54. A Novel Synthetic Approach to C-6 Carbon-substituted Pterins via Intermolecular 1,3Dipolar Cycloaddition Reactions (with P. S. Ray), J. Org. Chem., 56, 1812 (1991).

393. Structural Features of 5,10-Dideaza-5,6,7,8-tetrahydrofolate that Determine Inhibition of Mammalian Glycinamide Ribonucleotide Formyltransferase (with S. W. Baldwin, A. Tse, L. S. Gossett, A. Rosowsky, C. Shih and R. G. Moran), Biochemistry., 30, 1997 (1991).

394. Model Studies Directed Towards the Molybdenum Cofactor: 2-Alkylidene- and 2-Phenylimino-1,3dithiolenes from Acetylenes (with R. Dötzer), J. Org. Chem., 56, 1816 (1991).

395. Alternative Syntheses of N-[4'-(Alkoxycarbonyl)phenyl]-3-pyrrolidinones (with Z. Ahmed, D. J. Robke and R. J. Kempton), J. Org. Chem., 56, 5443-5445 (1991).

396. An Intramolecular 1,3-Dipolar Cycloaddition Approach to 5,6,7,8-Tetrahydro-(4-Ethoxy-6hydroxymethyl-2-pivaloylamino)-5-deazapteridin-5(8H)-one, a Potentially Useful Intermediate to 5-Deaza and 5,10-Dideaza-5,6,7,8-tetrahydrofolic Acid Analogs) with P. S. Ray), Heterocycles, 56, 1327-1340 (1991).

397. Mechanistic Aspects of the Oxidation of 1,3-Disubstituted 6-Amino-5-nitrosouracils with Lead Tetraacetate: Formation of Pyrimido[5,4-g]pteridinetetrone 10-Oxides (with M. Sako, S. Ohara, K. Hirota, K. Kano and Y. Maki), J. Org. Chem., 56, 6302 (1991). 
398. Model Complexes for the Molybdeopterin-Containing Enzymes and the Preparation and Crystallographic Characterization of a Molybdenum Ene-1-Perthiolate-2-Thiolate (Trithiolate) Complex (with R. S. Pilato, K. A. Eriksen, M. A. Greaney, E. I. Stiefel, S. Goswami, L. Kilpatrick, T. G. Spiro and A. L. Rheingold), J. Am. Chem. Soc., 113, 9372 (1991).

399. "Bicyclobenzodiazepinones" from 3-Oxo-1,2-diazetidinium Hydroxide, Inner Salts (with D. M. Sobieray), Tetrahedron, 47, 9599-9620 (1991).

400. Synthesis of 4-[2-(Guanin-8-yl)ethyl]benzoylglutamic Acid, a Guanine Analog of DDATHF (with D. Kuhnt and Z.-y. Chang), J. Org. Chem., 56, 6937 (1991).

401. Enaminones in the Preparation of 1,2-Diazetidin-4-ones (with John V. Greenhill), Heterocycles, 32, 2417-2427 (1991).

402. Synthetic Studies on the Molybdenum Cofactor. An Efficient Synthesis of Dephospho ( \pm )-Form A (with S. Goswami), Tetrahedron Lett., 32, 7357 (1991).

403. Chemistry Related to the Structure, Spectra and Reactivity of Molybdopterin (Mo-co) Dependent Enzymes (with E. I. Stiefel, R. S. Pilato, K. Ericksen, M. A. Greaney, S. Goswami, L. Kilpatrick, T. G. Spiro and A. L. Rheingold), J. Inorg. Biochem., 574 (1991).

404. Synthesis of 10-Substituted "Open-Chain" DDATHF Analogues (with T. H. Schrader and L. D. Walensky), Tetrahedron, 48, 19-32 (1992).

405. A Simple Aza Wittig-Mediated Pyrimidine Annulation Reaction (with Mona Patel), J. Heterocyclic Chem., 28, 1857 (1991).

406. Synthesis and Biological Activity of Acyclic Analogues of DDATHF (with C. Shih, L. S. Gossett, J. F. Worzalla, S. M. Rinzel, G. B. Grindey, R. G. Moran and P. M. Harrington), J. Med. Chem., 35, 1109 (1992)..

407. Novel 5-Desmethylene Analogues of 5,10-Dideaza-5,6,7,8-tetrahydrofolic Acid as Potential Anticancer Agents (with Paul Gillespie and Mona Patel), J. Org. Chem., 57, 3218 (1992).

408. Synthesis and Biological Activity of Nor-5,10-Dideazatetrahydrofolic Acid and Homo-5,10Dideazatetrahydrofolic Acid (with C. Shih, G. B. Grindey and P. M. Harrington), Bioorganic and Medicinal Chemistry Letters, 2, 339 (1992).

409. Further Acyclic Analogues of 5,10-Dideaza-5,6,7,8-tetrahydrofolic Acid (DDATHF, Lometrexol), (with Paul Gillespie), J. Org. Chem., 57, 5757 (1992).

410. A Dideazatetrahydrofolate Analogue Lacking a Chiral Center at C-6, N-\{4-[2-(2-Amino-1,7-dihydro-4oxopyrrolo[2,3-d]pyrimidin-6-yl)ethyl]benzoyl /glutamic Acid, is an Inhibitor of Thymidylate Synthase (with Dietmar Kuhnt, Chuan Shih, Sharon M. Rinzel, Gerald B. Grindey, Julio Barredo, Mehrdad Jannatipour, and Richard G. Moran), J. Med. Chem., in press.

411. Why are Isoxazoles Unreactive in Diels-Alder Reactions? An AB Initio Computational Study (with J. Gonzalez and K. N. Houk), J. Org. Chem., 57, 3753 (1992).

412. The Synthesis and Biological Activity of Pyrazolo[3,4-d]pyrimidine Analogues of the Potent Antitumor Agent $\mathrm{N}-\{4-[2-(2-A m i n o-4(3 \mathrm{H})$-oxo-7H-pyrrolo[2,3-d]pyrimidin-5-yl)ethyl]benzoyl $\}$ glutamic Acid (LY231514) (with Hemantkumar H. Patel), Tetrahedron, 48, 8089 (1992). 


\section{Edward C. Taylor}

\section{Books}

Advances in Organic Chemistry; Methods and Results (with R.A. Raphael and H. Wynberg, ed.), Interscience, New York
Vol. I, 1960, 387 pp.
Vol. II, 1960, 503 pp.
Vol. III, 1963, 333 pp.
Vol. IV, 1963, 359 pp.
Vol. V, 1965,335 pp.

Pteridine Chemisty (with W. Pfleiderer, ed.), Pergamon, Oxford, 1964, 560 pp.

Advances in Organic Chemistry: Methods and Results. Vol. VI (with H.Wynberg, ed.), Interscience, New York, 1969, $432 \mathrm{pp}$.

The Chemistry of Cyclic Enaminonitriles and o-Aminonitriles (with A. McKillop), Wiley-Interscience, New York, $1970,415 \mathrm{pp}$.

The Heterocyclic Derivatives of Phosphorus, Arsenic, Antimony, and Bismuth, Second Edition, by F.G. Mann (with A. Weissberger, ed.), Interscience, New York, 1970. 740 pp. (Vol. 1).

The Pyrimidines, Supplement 1, by D.J. Brown (with A. Weissberger, ed.), Interscience, New York, 1970, $912 \mathrm{pp}$.

Purines, by J.H. Lister (with A. Weissberger, ed.), Wiley-Interscience, New York 1971, 655 pp.

Mass Spectrometry of Heterocyclic Compounds, by Q.N. Porter and J. Baldas (with A. Weissberger, ed. Wiley-Interscience, New York, 1971, 564 pp.

7-Membered Heterocyclic Compounds Containing Oxygen and Sulfur (A. Rosowsky, ed.) (with A. Weissberger, ed.), Wiley-Interscience, New York, 1972,949 pp.

Indoles, Part I, (W.J. Houlihan, ed.) (with A. Weissberger, ed.), Wiley-Interscience, New York, 1972, 587 pp.

Indoles, Part II, (W.J. Houlihan, ed.) (with A. Weissberger, ed.), Wiley-Interscience, New York, 1972, 616 pp.

Advances in Organic Chemistry: Methods and Results. Vol. VIII, Wiley-Interscience, New York, 1972, 459 pp.

Condensed Pyridazines Including Cinnolines and Phthalazines (R.N. Castle, ed.) (with A. Weissberger, ed.), Wiley-Interscience, New York, 1973, 1124 pp.

Pyridazines (R.N. Castle, ed.) (with A. Weissberger, ed.), Wiley-Interscience, New York, 1973, 905 pp.

NMR Spectra of Simple Heterocycles (T. J. Batterham) (with A. Weissberger, ed.), Wiley-Interscience, New York, 1973, $540 \mathrm{pp}$. 
Benzofurans (A. Mustafa) (with A. Weissberger, ed.), Wiley-Interscience, New York, 1974, 514 pp.

Heterocycles in Organic Synthesis (A.I. Meyers) (with A. Weissberger, ed.), Wiley-Interscience, New York, 1974,332 pp.

Principles of Heterocyclic Chemistry - An ACS Film Course, American Chemical Society, Washington, D.C., 1974,217 pp., plus 24 hours of filmed lectures.

Pyridine and its Derivatives (R.A. Abramovitch, ed.), Vol. 14, Supplement, Part 3 (with A. Weissberger, ed.), Wiley-Interscience, New York, 1974, 1249 pp.

Principles of Heterocyclic Chemistry - An ACS Audio Course, Parts I and II, American Chemical Society, Washington, D.C., 1974, 212 pp., plus 12 hours of tape cassettes.

Pyridine and its Derivatives (R.A. Abramovitch, ed.), Vol. 14, Supplement, Part 1 (with A. Weissberger, ed.), Wiley-Interscience, New York, 1974, 451 pp.

Pyridine and its Derivatives (R.A. Abramovitch, ed.), Vol. 14, Supplement, Part 2 (with A. Weissberger, ed:), Wiley-Interscience, New York, 1974, 661 pp.

Pyridine and its Derivatives (R.A. Abramovitch, ed.), Vol. 14, Supplement, Part 4 (with A. Weissberger, ed.), Wiley-Interscience, New York, 1974, 720 pp.

Photochemistry of Heterocyclic Compounds (O. Buchardt, ed.), (with A. Weissberger, ed.), WileyInterscience, New York, 1976, 662 pp.

Special Topics in Heterocyclic Chemistry (with A. Weissberger, ed.), Wiley-Interscience, New York, N.Y., $1977,601 \mathrm{pp}$.

Iminium Salts in Organic Chemistry. Part 1 (H. Bohme and G.H. Viehe, eds.), Volume 9 in the series Advances in Organic Chemistry (E.C. Taylor, ed.), Wiley-Interscience, New York, 1976, 631 pp.

Chromenes, Chromanones and Chromones (G. P. Ellis, ed.), (with A. Weissberger, ed.), Wiley-Interscience, New York, $1977,1196 \mathrm{pp}$.

Stereochemistry of Heterocyclic Compounds, Part 1; Nitrogen Heterocycles (W. L. F. Armarego) (with A. Weissberger, ed.), Wiley-Interscience, New York, 1977,443 pp.

Stereochemistry of Heterocyclic Compounds. Part 2; Oxygen. Sulfur. Mixed N, O and S. and Phosphorus Heterocycles (W. L. F. Armarego) (with A. Weissberger, ed.), Wiley-Interscience, New York, 1977, 494 pp.

Quinolines. Part 1 (G. Jones, ed.) (with A. Weissberger, ed.), Wiley-Interscience, New York, 1977, 898 pp.

Chemistry of 1.2.3-Triazines and 1.2.4-Triazines, Tetrazines, and Pentazines (H. Neunhoeffer and P.R. Wiley) (with A. Weissberger, ed.), Wiley-Interscience, New York, 1978, 1335 pp.

Iminium Salts in Organic Chemistry, Part 2 (H. Bohme and G.H. Viehe, eds.), volume 9 in the series Advances in Organic Chemistry (E. C. Taylor, ed.), Wiley-Interscience, New York, 1979.

Thiazole and its Derivatives. Part 1 (J.V. Metzger, ed.) (with A. Weissberger, ed.), Wiley-Interscience, New York, 1979, 612 pp. Thiazole and its Derivatives, Part 2 (J.V. Metzger, ed.) (with A. Weissberger, ed.), Wiley-Interscience, New
York, 1979, 773 pp. Thiazole and its Derivatives. Part 3 (J.V. Metzger, ed.) (with A .Weissberger, ed.), Wiley-Interscience, New
York, 1979,407 pp. 
Condensed Pyrazines (G.W.H. Cheeseman and R.F. Cookson, eds.), (with A. Weissberger, ed.), WileyInterscience, New York, 1979, 835 pp.

Indoles. Part 3 (W. J. Houlihan, ed.) (with A. Weissberger, ed.), Wiley-Interscience, New York, 1979, 586 pp.

Triazoles. 1.24 (C. Temple, Jr. and J.A. Montgomery) (with A. Weissberger, ed.) Wiley-Interscience, New York, 1981, 791 pp.

Triazoles, 1.2.3 (K.T. Finley and J.A. Montgomery) (with A. Weissberger, ed.) Wiley-Interscience, New York, $1980,349 \mathrm{pp}$.

Isoquinolines. Part 1 (G. Grethe, ed.) (with A. Weissberger, ed.), Wiley-Interscience, New York, 1981, 561 pp. (Vol. 38).

Chromans and Tocopherols (G.P. Ellis and I.M. Lockhart, eds.) (with A. Weissberger, ed.), John Wiley \& Sons, New York, 1981, 469 pp. (Vol. 36).

Benzimidazoles and Congeneric Tricyclic Compounds. Part 1 (P.N. Preston, ed.) (with A. Weissberger, ed.), Wiley-Interscience, New York, 1981, 681 pp. (Vol. 40).

Benzimidazoles and Congeneric Tricyclic Compounds. Part 2 (P.N. Preston, ed.) (with A. Weissberger, ed.), Wiley-Interscience, New York, 1981, 581 pp.

Small Ring Heterocycles: Aziridines, Azirines. Thiiranes and. Thiirenes, Part 1 (A. Hassner, ed.) (with A. Weissberger, ed.), Wiley-Interscience, New York, 1983, 969 pp. (Vol. 42).

Small Ring Heterocycles: Azetidines, $\beta$-Lactams, Diazetidines and Diaziridines, Part 2 (A. Hassner, ed.) (with A. Weissberger, ed.), Wiley-Interscience, New York, 1983, 656 pp. (Vol. 42).

Azepines, Part 1 (A. Rosowsky, ed.) (with A. Weissberger, ed.), Wiley-Interscience, New York, 1984, 282 pp. (Vol. 43).

Azepines, Part 2 (A. Rosowsky, ed.) (with A. Weissberger, ed.), John Wiley and Sons, 1984, 889 pp. (Vol. 43).

1.3-Dipolar Cycloaddition Chemistry Vol. 1 (A. Padwa, ed.) (with A. Weissberger, ed.), Wiley-Interscience, New York, 1984, $817 \mathrm{pp}$.

1,3-Dipolar Cycloadition Chemistry Vol. 2 (A. Padwa, ed.) (with A. Weissberger, ed.), Wiley-Interscience, New York, 1984, 704 pp.

Physical Methods in Heterocyclic Chemistry (R.R. Gupta, ed.) (with A. Weissberger, ed.), Wiley-Interscience, New York, $1984,682 \mathrm{pp}$.

Pyridine and Its Derivatives. Part 5 (G.R. Newkome, ed.) (with A. Weissberger, ed.), John Wiley and Sons, New York, 1984, 714 pp. (Vol. 14).

Thiophene and Its Derivatives, Part 1 (S. Gronowitz, ed.) (with A. Weissberger, ed.), John Wiley and Sons, New York, 1985, 840 pp. (Vol. 44).

Small Ring Heterocycles: Oxiranes, Arene Oxides, Oxaziridines, Dioxetanes, Thetanes, Thietes, Thiazetes, and Qthers, Part 3 (A. Hassner, ed.) (with A. Weissberger, ed.), Wiley-Interscience, New York, 1985, 874 pp. (Vol. 42).

Mass Spectometry of Heterocyclic Compounds (Q.N. Porter, ed.) (with A. Weissberger, ed.), WileyInterscience, New York, 1985, 966 pp. 
Pyridine-Metal Complexes. Parts 6A.B.C (P. Tomasik and Z. Ratajewics; G.R. Newkome and L. Strekowski, eds.) (with A. Weissberger, ed.), Wiley-Interscience, New York, 1985, 2247 pp.

The Pyrimidines. Supplement II (D.J. Brown) (with A. Weissberger, ed.), Wiley-Interscience, New York, 1985,916 pp.

Oxazoles (IJ. Turchi, ed.) (with A. Weissberger, ed.), Wiley-Interscience, New York, 1986, 1064 pp. (Vol. 45).

Thiophene and Its Derivatives. Part II(S. Gronowitz, ed.) (with A. Weissberger, ed.), Wiley-Interscience, New York, 1986, 906 pp. (Vol. 44).

Thiophene and Its Derivatives, Part III (S. Gronowitz, ed.) (with A. Weissberger, ed.), Wiley-Interscience, New York, 1986, 1272 pp. (Vol. 44).

Synthesis of Fused Heterocycles (G. P. Ellis) (E. C. Taylor, ed)., John Wiley \& Sons, Chichester, England, 1987,660 pp.(Vol. 47).

Fused Pyrimidines, Part III. Pteridines (D. J. Brown) (E. C. Taylor, ed)., John Wiley \& Sons, New York, 1988, 730 pp (Vol. 24, part 3).

Pyrroles. Part I (R. A. Jones, ed.) (E. C. Taylor, ed), John Wiley \& Sons, New York, 1990, 742 pp. (Vol.

Quinolines. Part II (G. Jones, ed) (E. C. Taylor, ed), John Wiley \& Sons, Chichester, England, 1990.

Quinolines. Part III (G. Jones) (E. C. Taylor, ed), John Wiley \& Sons, Chichester, England, 1990, 560 pp.

Isoxazoles. Part I (P. Grünanger and P. Vita-Finzi) (E. C. Taylor, ed), John Wiley \& Sons, New York, 1991, $877 \mathrm{pp}$.

Thiophene and its Derivatives. Part 4 (S. Gronowitz, ed) (E. C. Taylor, ed), John Wiley \& Sons, New York, 1991,517 pp.

Bicyclic Diazepines (R. Ian Fryer, ed) (E. C. Taylor, ed), John Wiley \& Sons, New York, 1991, 1100 pp.

Thiophene and its. Derivatives. Part 5 (S. Gronowitz, ed.) E. C. Taylor, ed), John Wiley \& Sons, New York, 1992, $917 \mathrm{pp}$.

Synthesis of Fused Heterocycles. Part 2 (G. P. Ellis) (E. C. Taylor, ed), John Wiley \& Sons, New York, 1992, pp. 661-1430.

Pyrroles. Part 2 (R. Alan Jones, ed) (E. C. Taylor, ed), John Wiley \& Sons, New York, 1992, 628 pp. (Vol. 48) 